\title{
Las producciones de Terra Sigillata Altoimperial de Sisapo (La Bienvenida, Ciudad Real) II. Terra Sigillata Hispánica
}

\author{
Carmen Fernández Ochoa * y M. Mar Zarzalejos Prieto *
}

La Terra Sigillata Hispánica constituye el conjunto mejor representado en el marco de las producciones de vajilla fina romana proporcionadas por el yacimiento sisaponense.

Presentamos en esta ocasión, el análisis de los ejemplares de fabricación hispana atendiendo a la distinción de los centros productores de que se abasteció este núcleo. Nuestro trabajo finaliza con una valoración global acerca de la evolución cronológica y comercial reflejada por las tres producciones de Terra Sigillata Altoimperial identificadas en el yacimiento: TSI, TSG y TSH, tras presentar las dos primeras en el anterior número de esta misma publicación.

\section{TERRA SIGILLATA HISPÁNICA}

TSH procedente del centro de producción de Andújar

Formas lisas

1. Forma Drag. $15 / 17$ completa (fig. $6, n .{ }^{\circ} 1$ ). Barniz tierra siena brillante (S-37) y pasta tierra siena tostada (N-47) con desgrasantes finos amarillentos y fractura regular. Presenta labio marcado al exterior mediante una moldura, y pared oblícua, de trayectoria algo cóncava. La articulación

* (Dpto de Preh. y Arq U.A.M.). 
entre la pared y el fondo externo, se encuentra reforzada por una moldura convexa. En el interior, esta unión se verifica mediante la característica moldura en cuarto de círculo, de curvatura muy pronunciada en este caso. Ostenta pie elevado, de sección triangular, articulado con el fondo externo en un único movimiento. Los rasgos morfológicos documentados en este ejemplar, permiten adscribirle a la primera de las variantes definidas para esta forma en el centro de producción de Andújar. Tal variedad parece mantener contactos, con los productos gálicos de época claudia y flavia. A este respecto, cabe suponer que entre los prototipos imitados y estas reproducciones hispánicas, no medie un margen temporal demasiado prolongado (RocA 1976, 33-36). Por su parte, Mayet inserta este tipo de perfil en época flavia, argumentando su relación con ciertos ejemplares contemplados por Oswald y Pryce (MAYET 1984, II, lám. XXII, n. ${ }^{\circ 1} 12$ y 4; Oswald-Pryce 1966, lám. XLII, n. ${ }^{\circ 3} 37-39$ ).

2. Forma Drag. $15 / 17$ conservada prácticamente en su totalidad (fig. 6, n. ${ }^{\circ}$ ). Barniz tierra siena brillante (R-39) y pasta tierra siena tostada $(\mathrm{N}-47)$ con desgrasantes finos amarillentos y fractura regular. Presenta un estrecho labio delimitado exteriormente por una ranura y pared oblícua. El punto de unión entre la pared y el fondo externo, cuenta con doble orden de molduras. El cuarto de círculo interior, ofrece un perfil de curvatura menos acusada que en el caso precedente. Conserva pie elevado, de sección triangular y fondo interno provisto de un ligero abultamiento central. La presencia de molduración externa, parecen inscribir esta pieza en el mismo grupo reseñado para el ejemplar anterior.

3. Fragmento de base de forma Drag. 15/17 (fig. 6, n. ${ }^{\circ}$ 3). Barniz tierra siena brillante (S-37) y pasta tierra siena tostada ( $\mathrm{N}-47$ ) con desgrasantes finos amarillentos y fractura regular. Presenta pie no muy elevado, de sección rectangular. El fondo interno, de trayectoria bastante horizontal, conserva una marca de oficina casi completa, inscrita en cartela rectangular. La lectura propuesta en [E]X.OF.GI.C. El propio yacimiento de Andújar ha proporcionado un sello semejante sobre una forma Drag. 27 recogida en superficie (SотоMAYOR 1972, 274, fig. 3, n. ${ }^{\circ} 28$ ). Marcas de este mismo ceramista, se encuentran documentadas en Volúbilis, sobre Drag. 27 (BOUBE 1965, n. ${ }^{\circ} 333$ ), Banasa (Boube 1965, 237, n. ${ }^{\circ} 332$ ) y Riotinto, sobre forma Drag. 15/17 (DOMERGUE 1967, 44-45).

4. Fragmento de base de forma Drag. $15 / 17$ (fig. 6, n. ${ }^{\circ}$ 4). Barniz tierra siena brillante (S-37) y pasta tierra siena tostada (N-47) con desgrasantes finos amarillentos y fractura regular. Presenta pie no muy elevado, de sección triangular. En el fondo interno conserva parte de una marca en deficiente estado de conservación. Pese a su dificultad de lectura, podría reconocerse ...E.X OPC... En cualquier caso, no ha sido posible identificar 

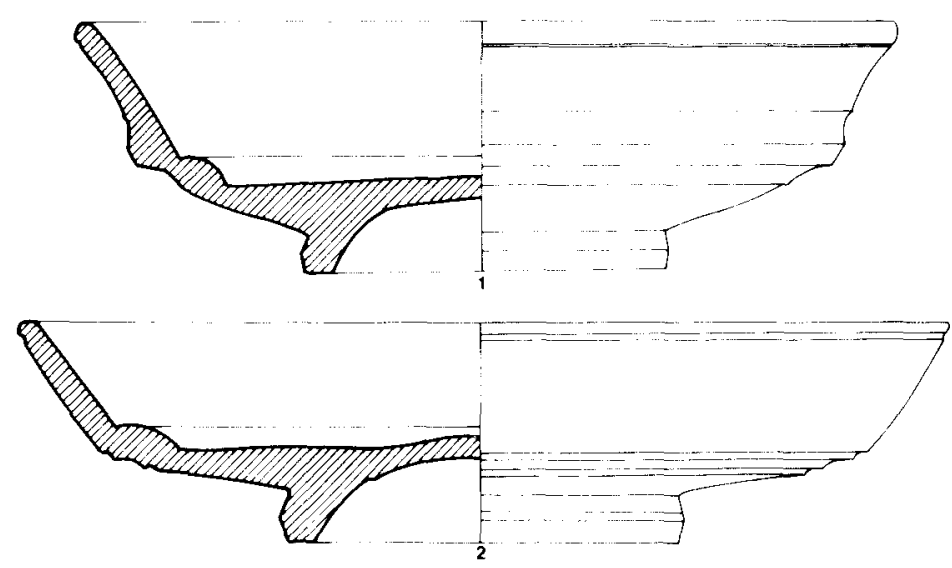

s.

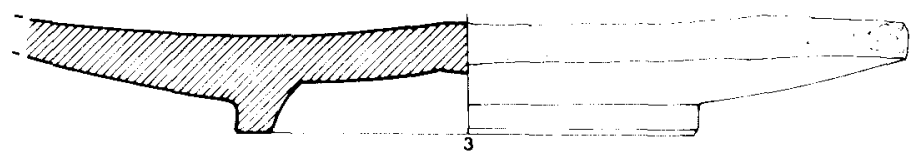

seto
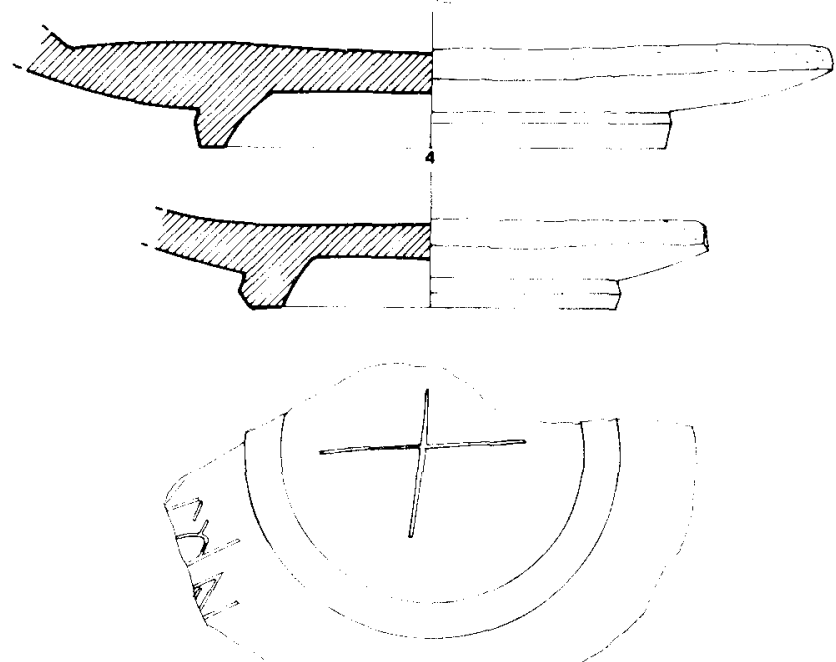

5

0

Fig. 6 . 
la oficina a que corresponde, aún cuando por sus caracteres externos de pasta y barniz parece estar vinculada sin duda, con los productos de Andújar. Morfológicamente, mantiene contactos con el segundo grupo instituido por Roca, en el conjunto de la forma 15/17 fabricada en este centro giennense (RocA 1976, fig. 18, n. ${ }^{\text {os }} 6-14$ y 16-18).

5. Fragmento de base de posible forma Drag. 15/17 (fig. 6, n. ${ }^{\circ}$ ). Barniz rojo venecia (S-20) brillante en el interior y mate en el exterior y pasta tierra siena tostada ( $\mathrm{N}-47$ ) con desgrasantes finos amarillentos y fractura irregular. Presenta pie de características análogas a las del ejemplar precedente. En el fondo externo, conserva un gráfico cruciforme y restos de otro, en una zona de la pared próxima al pie. De este último tan sólo puede leerse NRVA.

6. Fragmento de base de posible forma Drag. 15/17 (fig. 7, n. ${ }^{\circ}$ ). Barniz tierra siena brillante (R-39) y pasta tierra siena tostada (N-47) con desgrasantes finos amarillentos y fractura irregular. Presenta pie poco elevado, de sección rectangular. El fondo externo conserva parte de un grafito no identificable.

7. Fragmento de base de posible forma Drag. 15/17 (fig. 7, n. ${ }^{\circ}$ ). Barniz tierra siena brillante (R-39) y pasta tierra siena tostada (N-47) con desgrasantes finos amarillentos y fractura irregular. Presenta pie bajo, de sección rectangular y fondo externo, provisto de un grafito ejecutado con caracteres arcaicos: SEVERAI.

8. Fragmento de base y pared de forma Drag. 15/17 (fig. 7, n. ${ }^{\circ} 3$ ). Barniz tierra siena mate (S-37) y pasta tierra siena tosatada $(\mathrm{N}-47)$ con desgrasantes finos y fractura irregular. Presenta pie bajo, de sección rectangular. La unión entre la pared y el fondo externo aparece marcada por una ranura. El cuarto de círculo interior, conservado en su totalidad, presenta notable anchura y ligera tendencia aplanada.

9. Fragmento con perfil completa de forma Drag. 15/17 (fig. 7, n. ${ }^{\circ} 4$ ). Barniz tierra siena poco brillante (S-37) y pasta ocre carne (N-45) con desgrasantes finos amarillentos. Presenta pared muy oblícua, provista de cierto perfil acampanado y separada del fondo externo mediante una ranura. La moldura en cuarto de círculo situada en el punto de articulación entre la pared y el fondo interno, resulta estrecha y menos prominente que en el ejemplar anterior. Ostenta pie bajo, de sección rectangular. El fondo externo conserva grafitos de dudosa interpretación: LCIV N(...)NS. Desde el punto de vista morfológico, esta pieza parece corresponder a un momento avanzado de la producción de Andújar. En este sentido, ofrece interesantes contactos con un ejemplar procedente de Almedinilla (Mezquiriz 1961, II, lám. 12, n. ${ }^{\circ} 11$ ). 

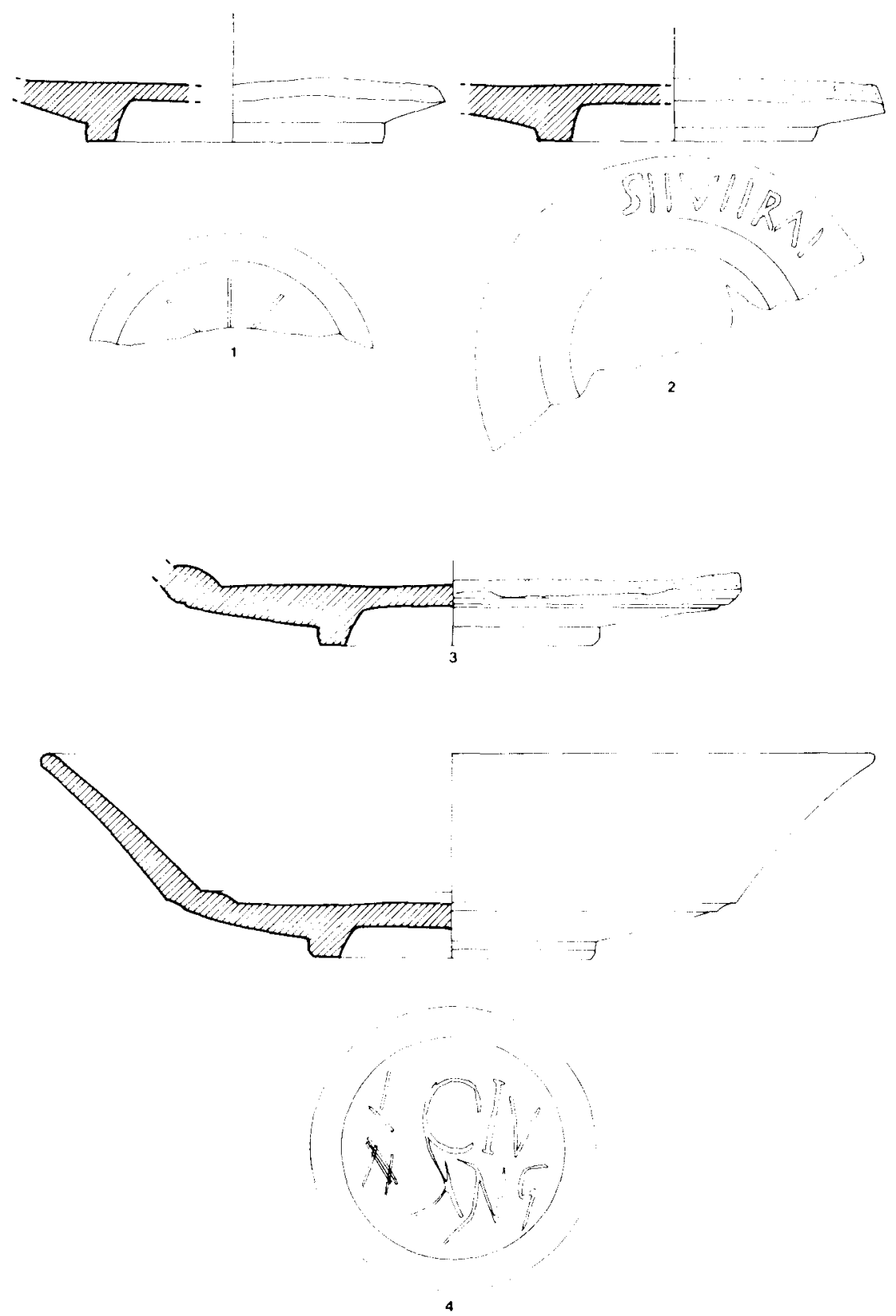

0

Fig. 7. 
10. Fragmento de base de forma Drag. 15/17 (fig. 8, n. ${ }^{\circ} 1$ ). Barniz tierra siena mate (R-39) y pasta ocre carne (N-45) con desgrasantes finos amarillentos y fractura regular. Presenta pie bajo, de sección rectangular y moldura en cuarto de circulo no muy pronunciada. En el fondo externo conserva parte de un grafito, en el que puede leerse EXP...

11. Fragmento de base de posible forma Drag. 15/17 (fig. 8, n. ${ }^{\circ}$ ). Barniz tierra siena mate (S-37) y pasta tierra y siena tostada ( $\mathrm{N}-47$ ) con desgrasantes finos amarillentos y fractura regular. Presenta pie de sección rectangular, extraordinariamente bajo. En el fondo externo aparecen restos de un grafito: $P$. IS (P)...

12. Fragmento de base de forma Drag. $15 / 17$ (fig. $8, n .{ }^{\circ} 3$ ). Barniz tierra siena mate (S-39) y pasta tierra siena tostada $(\mathrm{N}-47)$ con fractura regular. Presenta pie muy bajo, de sección rectangular. La moldura en cuarto de círculo resulta ancha y algo aplanada, mientras que el fondo interno mantiene una tendencia claramente ascendente.

13. Fragmento de base de forma Drag. 15/17 (fig. 8, n. ${ }^{\circ}$ ). Barniz tierra siena (S-37) brillante al interior y mate en la superficie externa y pasta tierra siena tostada (N-47) con desgrasantes finos amarillentos y fractura irregular. Presenta pie bajo, de sección rectangular. En el fondo externo, resulta visible un grafito de disposición cruciforme.

14. Fragmento de base de posible forma Drag. 15/17 (fig. 8, núm. 6). Barniz tierra siena brillante (S-37) y pasta tierra siena tostada (N-47) con desgrasantes finos amarillentos. Presenta pie bajo, de sección rectangular $y$ fondo interno de tendencia ascendente, con un grafito ejecutado en caracteres acaicos: MODERATIS.

15. Fragmento de base de posible forma Drag. 15/17 (fig. 8, n. ${ }^{\circ}$ ). Barniz tierra siena mate (S-39) y pasta ocre carne (N-45) con desgrasantes finos amarillentos y fractura irregular. Presenta pie muy bajo, de sección rectangular. En el fondo interno, conserva una marca de oficina incompleta, así como restos de un grafito en el que puede leerse ...TAR... El sello, del que únicamente resultan visibles tres letras, ...GIC, corresponde a la modalidad de cartela rectangular de extremos redondeados. Interpretamos que debe atribuirse al ceramista que con frecuencia firma EX OF GIC, documentado en Andújar sobre forma Drag. 27 (RoCA 1976, 18). Mercedes Roca apunta la posibilidad de que las firmas EX OF CIC, identificadas en Volúbilis y Banasa sobre Drag. 27 (Boube 1965, n. ${ }^{\circ} 33$ ) y Riotinto en forma 15/17 (Domergue 1967, 41; MAVET 1970, 160, n. ${ }^{\circ} 40$ ), puedan corresponder también a este mismo alfarero.

16. Fragmentos con perfil completo de forma Drag. 15/17 (fig. 9, n. ${ }^{0}$ ). Barniz tierra siena poco brillante (S-37) y pasta ocre carne (N-45) con des- 

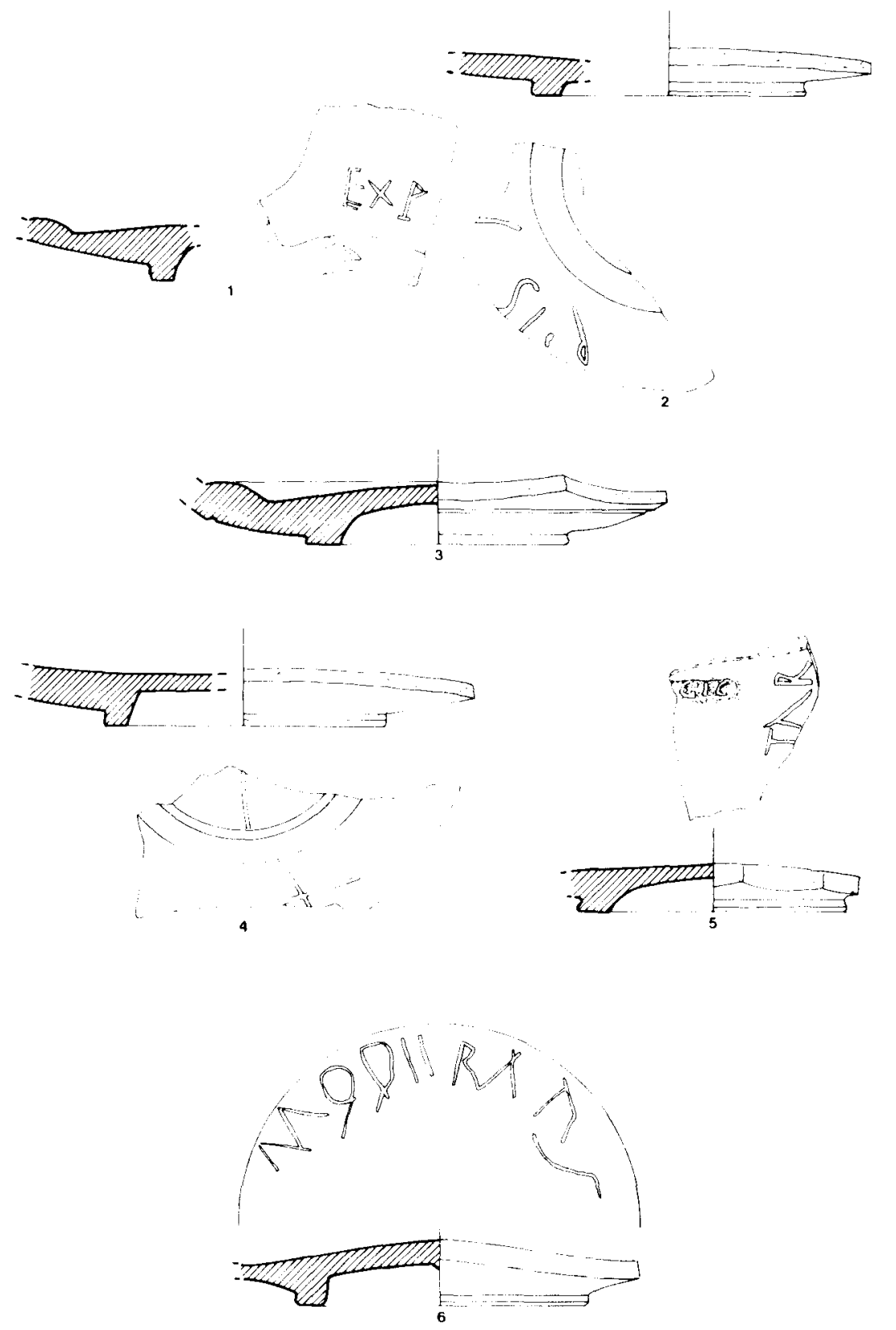

Fig. 8 . 
grasantes finos amarillentos. Presenta pared muy oblícua, de perfil ostensiblemente acampanado. Su articulación con el fondo interno, se encuentra reforzada por una ranura. Conserva pie bajo, de sección rectangular. La moldura interna en cuarto de círculo, describe una curva escasamente acentuada. En el fondo externo, se conserva un grafito cruciforme. Morfológicamente, este ejemplar participa de los rasgos avanzados que hemos ido anotando en piezas precedentes.

17. Forma Drag. 15/17 conservada prácticamente en su totalidad (fig. 9, $\mathrm{n} .{ }^{\circ}$ 2). Barniz tierra siena brillante (S-37) y pasta tierra siena tostada (N-47) con desgrasantes finos amarillentos. Su descripción formal resulta bastante próxima a la reseñada para el ejemplar anterior. Si acaso, podría destacarse la presencia de un pie, prácticamente inexistente al exterior. Perfiles similares han sido documentados en Andújar (MAYET 1984, I, 45; II, lám. XXII, n. ${ }^{\circ}$ 10). Conserva en la pared externa, un grafito en forma de creciente lunar.

18. Forma Drag. 15/17 conservada prácticamente en su totalidad (fig. 9, $\mathrm{n} .{ }^{\circ}$ 3). Barniz tierra siena mate (R-39) y pasta tierra siena natural clara ( $\mathrm{N}$ 37) con desgrasantes finos amarillentos. Su descripción reincide en los puntos formales documentados en las dos últimas piezas, aunque quizá convenga apuntar la existencia de cierta convexidad en la pared y la duplicación del diámetro del borde en relación al de la base. Esta configuración general del perfil, y las características físicas de pasta y barniz, inducen a pensar que nos hallamos ante el ejemplar más tardío de esta forma proporcionado por el yacimiento.

19. Fragmento de pared de forma Drag. 15/17 (fig. 9, n. ${ }^{\circ} 4$ ). Barniz tierra siena (S-39) y pasa tierra siena tostada ( $\mathrm{N}-47$ ) con desgrasantes finos amarillentos y fractura irregular. Conserva el punto de unión entre la pared y el fondo interno, con moldura en cuarto de círculo escasamente pronunciada. En la pared externa, resulta visible un grafito incompleto: ....N1...

20. Forma Drag. $24 / 25$ conservada prácticamente en su totalidad (fig. 10, n. ${ }^{\circ}$ ). Barniz tierra siena (S-39) brillante al interior y mate en la superficie externa y pasta ocre carne $(\mathrm{N}-45)$ con desgrasantes finos amarillentos y fractura regular. La porción superior de la pared registra una ligera incurvación hacia el interior. Presenta marcado baquetón moldurado, de sección cuadrangular. La zona inferior de la pared ostenta perfil oblícuo y restos de un grafito. Conserva pie alto, de sección triangular y fondo interno también provisto de un grafito incompleto. En cuanto al perfil general de la pieza, debe anotarse la particularidad de que la zona superior de la copa, limitada por el baquetón, resulta inferior a la mitad de la altura total. Tal característica resulta propia de las producciones sudgálicas atribuidas a época claudia (Oswald-Pryce 1966, lám. XL, n. ${ }^{\text {s }} 3$ 3-13). En nuestro caso, 

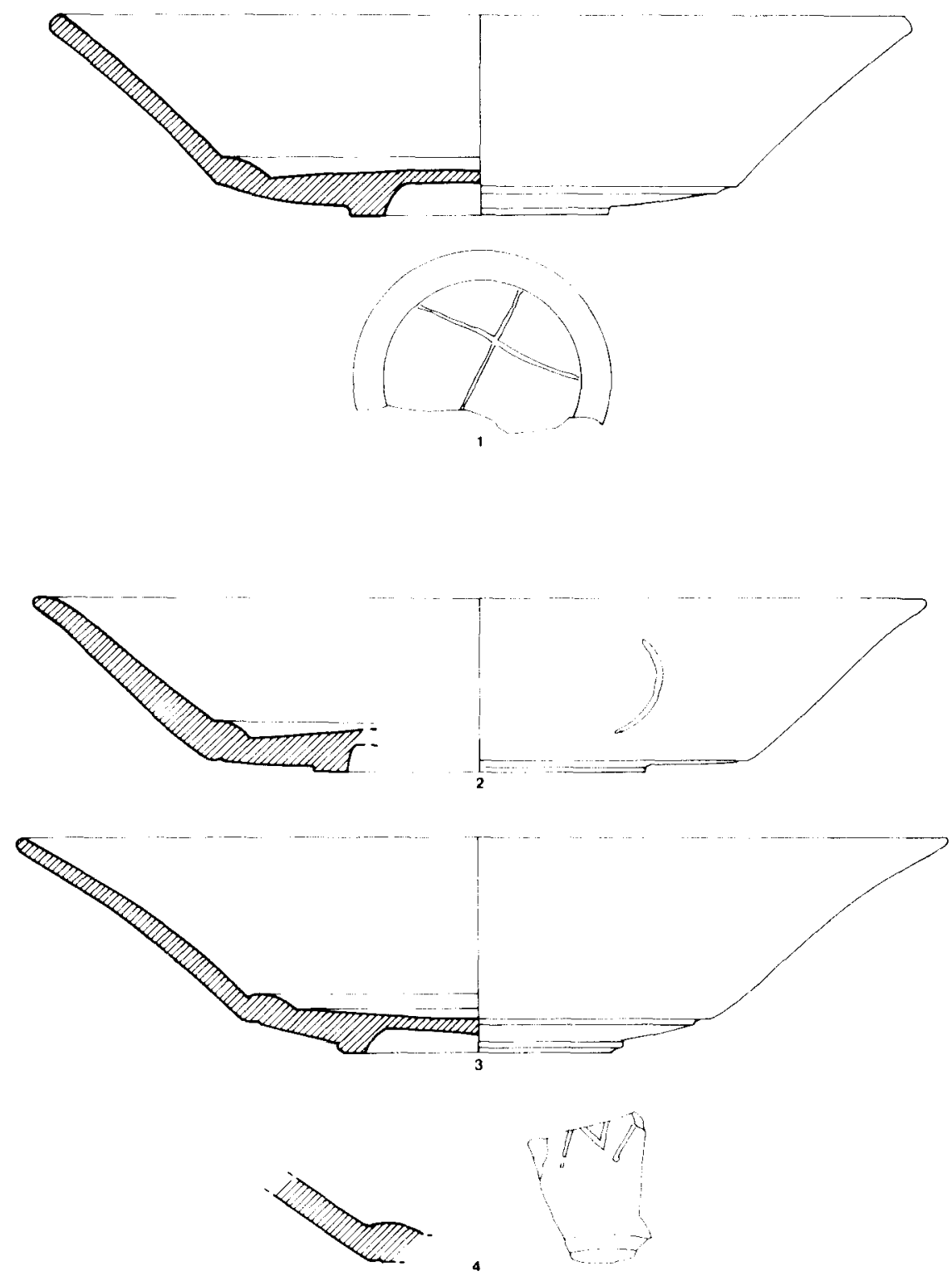

0 $5 \mathrm{~cm}$

Fig. 9 . 
se encuentran ausentes las ranuras internas o externas del borde. Una pieza de rasgos similares a los descritos, aunque provista de decoración burlada, se encuentra documentada en la propia Andújar e incluida por Roca en el primer grupo cronológico apuntado para la forma Drag. 15/17 (RocA 1976, 38 , fig. 19, n. $\left.{ }^{\circ} 19\right)$.

21. Fragmento de borde y pared de forma Drag. $24 / 25$ (fig. 10, n. ${ }^{\circ}$ ). Barniz tierra siena mate (S-37) y pasta tierra siena natural (N-57) con desgrasantes finos amarillentos y blancuzcos y fractura irregular. Presenta borde recto, desprovisto de labio y porción superior de la pared, de tendencia vertical. Conserva marcado baquetón moldurado, de sección algo triangular y arranque de la pared inferior, de trayectoria oblícua. Pese a su estado incompleto, parece que el baquetón estaría situado en el punto medio del vaso. Esta característica resulta ser la nota predominante en la producción de la forma en Andújar (RocA 1976, 38).

22. Fragmento de borde y pared de forma Drag. 24/25 (fig. 10, n. 3 ). Barniz tierra siena mate (S-39) y pasta tierra siena tostada ( $\mathrm{N}-47$ ) con desgrasantes finos amarillentos. Presenta borde algo incurvado hacia el interior, de sección redondeada y desprovisto de labio. Conserva baquetón de sección cuadrangular, situado aproximadamente en la zona media del vaso.

23. Forma Drag. 27 conservada prácticamente en su totalidad (fig. 10 , n. ${ }^{\circ}$ ). Los cuartos de círculo que articulan el perfil característico de esta forma, presentan un grado de curvatura poco acentuado, al tiempo que el correspondiente a la zona superior del vaso, resulta sensiblemente inferior al segundo. Presenta pie no muy elevado, de sección triangular y fondo externo provisto de molduración escasamente marcada. Esta última característca resulta impropia de las producciones de Drag. 27 en Andújar, aunque el mismo yacimiento giennense ha proporcionado dos ejemplares que la poseen (RocA 1976, 40, fig. 19, $n .{ }^{\text {os }} 43$ y 45). En el fondo interno, presenta un grafito en forma de aspa.

24. Forma Drag. 27 conservada prácticamente en su totalidad (fig. 10 , n. ${ }^{\circ}$ ). Barniz tierra siena (S-37) poco brillante en el interior y mate en la superficie externa y pasta tierra siena natural (N-57). La descripción de sus rasgos formales coincide con la apuntada para el ejemplar precedente, aunque en este caso, debe señalarse la ausencia de moldura en el fondo externo.

25. Forma Drag. 27 conservada prácticamente en su totalidad (fig. 10, n. ${ }^{\circ}$ ). Barniz tierra siena (S-37) poco brillante en el interior y mate en la superficie externa y pasta tierra siena natural (N-57). Este ejemplar resulta sensiblemente próximo al anterior, aunque provisto de curvatura más marcada en ambos cuartos de círculo. Conserva evidencias de una marca de 

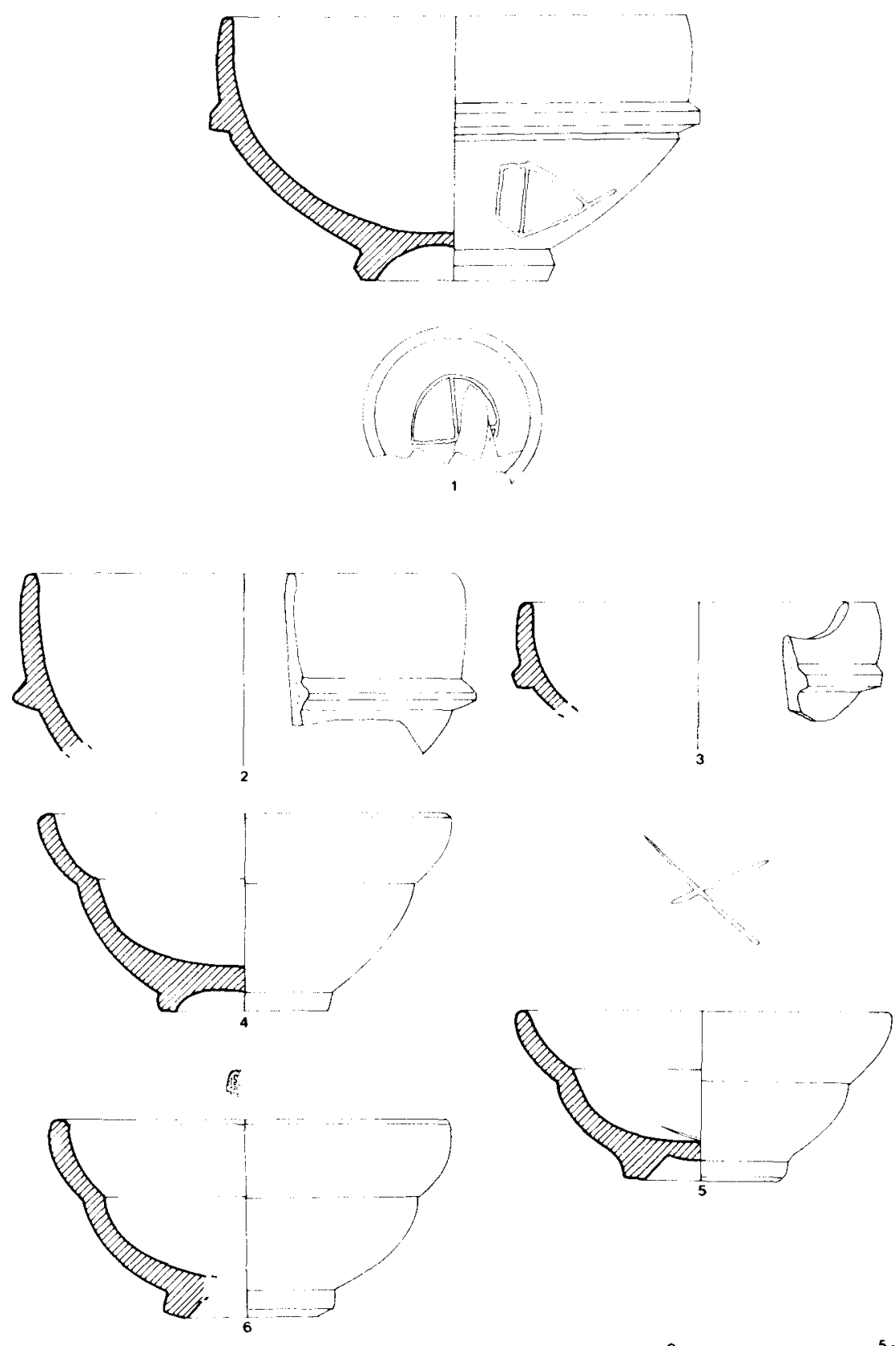

Fig. 10 . 
oficina inscrita, según parece, en cartela rectangular y de la que se conserva únicamente la letra $E$.

26. Fragmento de borde y pared de forma Drag. 27 (fig. 11, n. ${ }^{\circ} 1$ ). Barniz tierra siena poco brillante (S-37) y pasta tierra siena natural (N-57). Presenta las características formales apuntadas en los casos precedentes. En el interior del primer cuarto de círculo, conserva un grafito: SAB, y un segundo en la superficie externa, ubicado en el cuarto de círculo inferior, que puede ser descrito como un ángulo agudo, relleno con trazos paralelos.

27. Fragmento de borde y pared de forma Drag. 27 (fig. 11, n. ${ }^{\circ}$ ). Barniz tierra siena (R-39) y pasta tierra siena tostada ( $\mathrm{N}-47$ ) con desgrasantes finos amarillentos. Presenta un primer cuarto de círculo muy exvasado y con un grado de curvatura bastante acentuado, en contraposición al cuarto de círculo inferior, caso oblícuo y escasamente curvado. La excesiva curvatura de los cuartos de círculo, no constituyen un modelo frecuente en Andújar, aunque entre sus ejemplares se encuentran algunos provistos de este rasgo (RocA 1976, fig. 19, $n .{ }^{\circ 5} 34$ y 36).

28. Fragmento de borde y pared de forma Drag. 27 (fig. 11, n. ${ }^{\circ}$ ). Barniz tierra siena mate (R-39) y pasta tierra siena tostada (N-47) con desgrasantes finos y fractura irregular. Presenta borde exvasado, con labio desprovisto de ranuras y un primer cuarto de círculo de curvatura marcada. La presencia de un borde de este tipo, constituye un caso excepcional en las producciones del área andujareña, con la que parece estar vinculado nuestro ejemplar desde el punto de vista de la constitución física de pasta y barniz. No obstante, han sido documentados perfiles similares en la propia Andújar (MAYET 1984, II, lám. XXIV, n ${ }^{\text {os }} 28$ y 29).

29. Fragmento de base y pared de forma Drag. 27 (fig. 11, n. ${ }^{\circ}$ ). Barniz tierra siena brillante (S-37) y pasta ocre carne (N-45) con desgrasantes finos amarillentos. Presenta pie elevado, con sección de tendencia triangular y cuarto de círculo inferior de curvatura poco acentuada. En el superior, conserva restos de un grafito, constituido por dos trazos cortos paralelos.

30. Fragmento de base y pared de forma Drag. 27 (fig. 11, n. ${ }^{\circ}$ ) . Barniz tierra siena brillante (S-37) y pasta tierra siena tostada (N-47). Presenta pie elevado, de sección triangular y perfil de características análogas a las del ejemplar precedente. En el cuarto de círculo inferior, en zona próxima a la base, conserva un grafito, el parecer incompleto, en el que puede leerse ...FINUS NOTAX...

31. Fragmento de base de posible forma Drag. 27 (fig. 12, n. ${ }^{\circ}$ 1). Barniz tierra siena mate (R-39) y pasta tierra siena tostada (N-47) con des- 


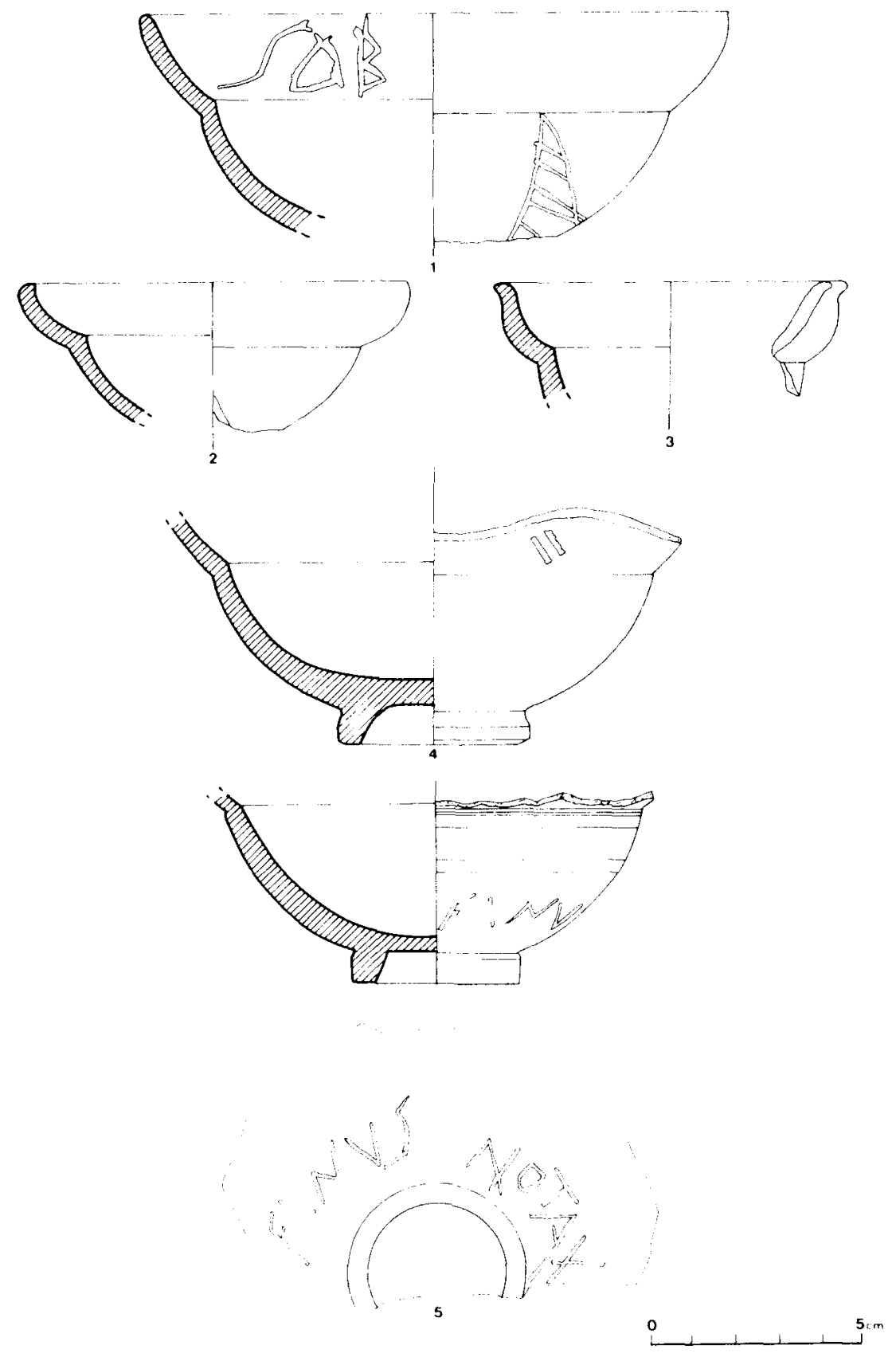

Fig. 11. 
grasantes finos amarillentos y fractura irregular. Presenta pie elevado, de sección triangular. Conserva varios grafitos emplazados en distintos puntos: en el fondo interno, dos trazos cruzados; en la pared externa próxima a la base, una $B$ retrógrada y en el fondo externo, cuatro trazos en forma de aspa.

32. Fragmento de base de posible forma Drag. 27 (fig. 12, n. ${ }^{\circ}$ ). Barniz tierra siena brillante (R-39) y pasta tierra siena tostada ( $N-47)$ con desgrasantes finos amarillentos y fractura irregular. Presenta pie elevado, de sección rectangular. En el fondo interno, conserva un grafito interpretado como $\mathrm{R}$ en disposición retrógrada.

33. Fragmento de base de posible forma Drag. 27 (fig. 12, n. ${ }^{\circ}$ ). Barniz tierra siena mate (S-37) y pasta tierra siena tostada (N-47) con desgrasante finos y fractura irregular. Presenta pie alto, de sección triangular y fondo externo con moldura excasamente marcada. Como se indicó a propósito de nuestra pieza $n .{ }^{\circ} 23$, la molduración del fondo externo no resulta un rasgo frecuente en la producción de Andújar. Conserva en el cuarto de círculo inferior, próximo al pie, restos de un grafito de imposible identificación ( $V \times A$ ?).

34. Fragmento de base de posible forma Drag. 27 (fig. 12, n. ${ }^{\circ}$ ). Barniz tierra siena brillante (S-37) y pasta tierra siena natural clara (N-37) con desgrasantes finos amarillentos y fractura regular. Presenta pie alto, de sección triangular. En el fondo externo conserva un grafito cruciforme, así como restos de otro, en un punto de la pared externa próximo a la base, del que únicamente puede reconocerse una posible $N$.

35. Fragmento de base y pared de forma Drag. 27 (fig. 12, n. ${ }^{\circ} 4$ ). Barniz tierra siena brillante (S-39) y pasta tierra siena tostada (N-47) con desgrasantes finos amarillentos fractura regular. Conserva pie no muy elevado, de sección triangular y fondo externo con molduración muy suave. En el cuarto de círculo inferior, presenta un grafito cruciforme. El fondo externo contiene un segundo grafito, constituido por un diseño pentagonal con trazos verticales y horizontales inscritos en su interior.

36. Fragmento de base de posible forma Drag. 27 (fig. 13, n. ${ }^{\circ}$ ). Barniz tierra siena brillante (S-37) y pasta tierra siena tostada $(\mathrm{N}-47)$ con desgrasantes finos amarillentos y fractura regular. Presenta pie alto, de sección triangular. En el fondo interno conserva una marca de oficina completa, inscrita en cartela rectangular de extremos redondeados. Puede leerse: EX OF P.T. Este sello se encuentra abundantemente representado en Andújar, asociado a la forma Drag. 27 y $15 / 17$ y provisto o no de puntuación (RocA 1976, 24-25; MAYET 1984, I, 164-166, n. ${ }^{\text {ss }} 503,508$ y 510). Así mismo, su dispersión ha podido ser acreditada a través de nu- 

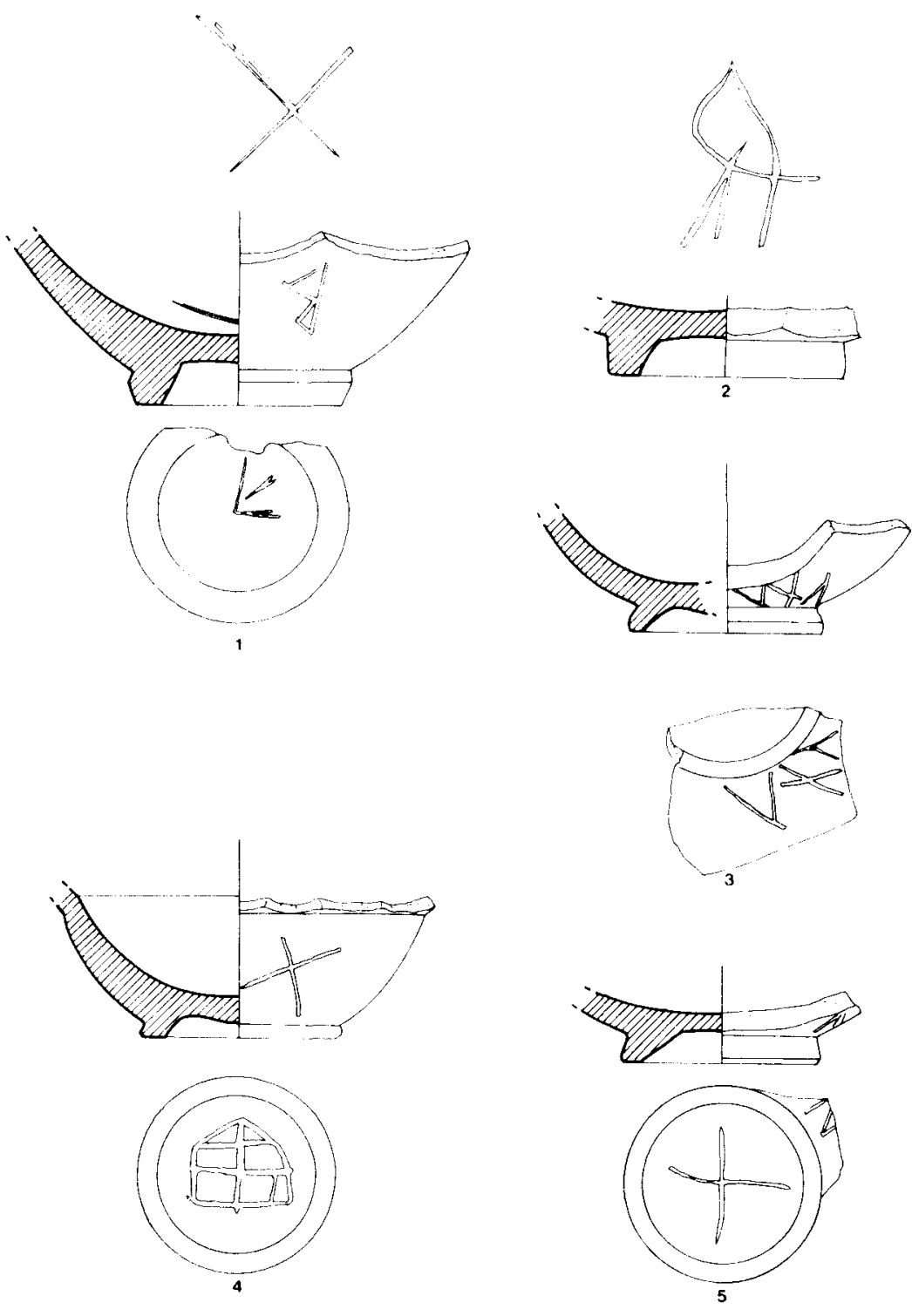

0 $5 \mathrm{~cm}$

Fig. 12. 
merosos hallazgos, puesto que, al margen de su presencia en la propia Andújar (Sotomayor 1972, 276, fig. 3, n. $^{\circ} 38$ ), ha sido identificada en Cástulo (Domergue 1967, 41, fig. 13), Chellah (Sala) (Boube 1965, 102, n. 87), Banasa y Volúbilis (Boube 1965, 247, $n .^{\circ} 361$ y 364). En este último yacimiento, aparece asociada a un contexto material datable entre fines del siglo I y la primera mitad del II d.C.

37. Fragmento de base de posible forma Drag. 27 (fig. 13, n. ${ }^{\circ}$ ). Barniz tierra siena brillante (S-37) y pasta tierra siena tostada ( $N-47)$ con desgrasantes finos amarillentos y fractura irregular. Presenta pie elevado, de sección triangular. Conserva una marca de oficina incompleta, inscrita en cartela rectangular de extremos redondeados, de impresión algo defectuosa. Puede leerse: EX OF C... A nuestro juicio, resulta probable su identificación con la firma EX OF CA, abundantemente documentada en el centro de producción de Andújar (RocA 1976, 16-17) y de probada dispersión en Mauritania (Boube 1965, n. ${ }^{\text {os } 300-309) . ~}$

38. Fragmento de base de posible forma Drag. 27 (fig. 13, n. ${ }^{\circ} 3$ ). Barniz tierra siena brillante (S-37) y pasta ocre carne (N-45) con desgrasantes finos amarillentos y fractura irregular. Presenta pie elevado, con sección de tendencia triangular. Conserva una marca de oficina completa, inscrita en cartela rectangular de extremos redondeados, en la que puede leerse: EX OF CA. El sello corresponde al mismo ceramista identificado en el ejemplar precedente. Resulta especialmente similar a las marcas reconocidas sobre sendas piezas procedentes de Andújar, en forma Drag. 27 (MAYET 1984, I, 123, n. ${ }^{\text {os }} 82$ y 83 ).

39. Fragmento de base de posible forma Drag. 27 (fig. 13, n. ${ }^{\circ}$ ). Barniz tierra siena brillante (R-39) y pasta tierra siena tostatada (N-47) con desgrasantes finos amarillentos y fractura granulosa. Presenta pie elevado, con sección de tendencia triangular y fondo externo con moldura escasamente marcada. Conserva una marca de oficina incompleta, inscrita en cartela rectangular. Debe corresponder, sin duda, al alfarero andujareño que adoptó el sello EX O TIF (SOTOMAYOR 1972, 276, fig. 3, n. ${ }^{\text {os }} 39-41$; Roca 1976, 26, n. ${ }^{\circ \mathrm{s}} 61-63$; MAYET 1984, I, 1 78, n. ${ }^{\circ 5}$ 638-639). La misma marca ha podido ser identificada en Cástulo sobre forma Drag. 15/17 (DOMERGUE 1967, 41), Volúbilis, Souk-el-Arba y Banasa (Boube 1965, n. ${ }^{\text {os }} 368-370$ ). Morfológicamente, esta base de posible forma Drag. 27, resulta próxima a uno de los ejemplares ilustrados por Sotomayor (SoTOMAYOR 1972, 27, fig. 6 , n. ${ }^{\circ} 8$ ).

40. Fragmento de borde y pared de forma Drag. 44 (fig. 13, n. $^{\circ} 5$ ). Barniz tierra siena brillante (S-37) y pasta tierra siena tostada ( $\mathrm{N}-47$ ) con desgrasantes amarillentos y fractura irregular. Presenta el borde característico en la forma, de perfil cóncavo al interior y convexo en la superficie 


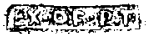

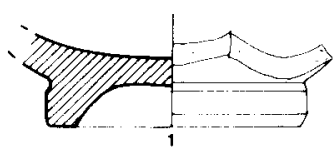

CROBW
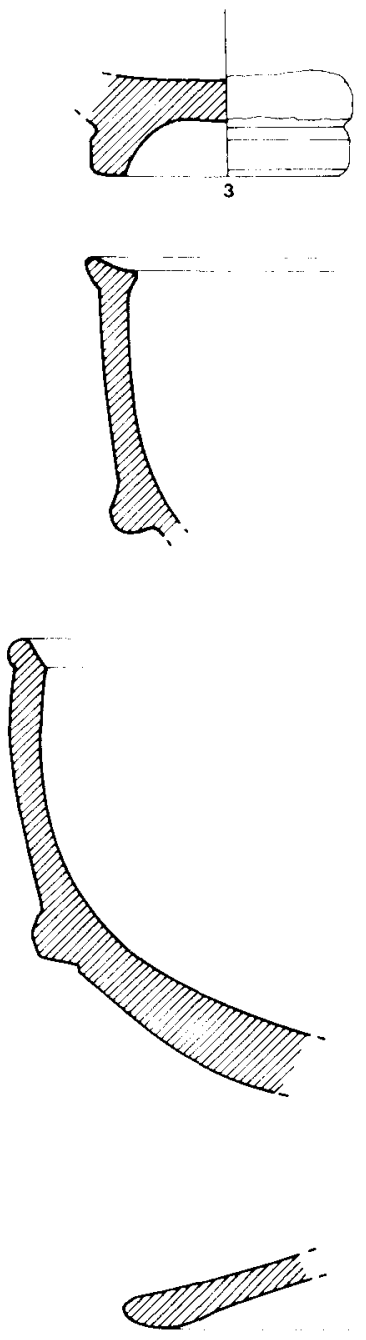
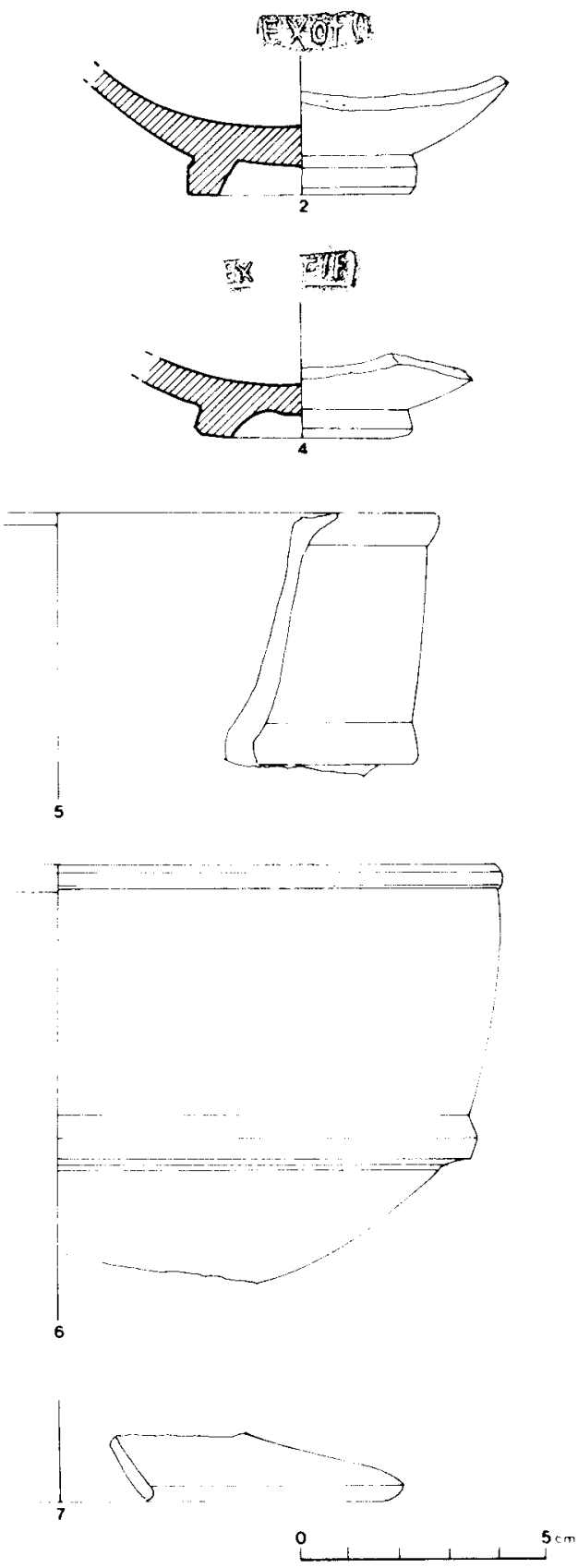

Fig. 13. 
externa. El primer tramo de la pared, manifiesta clara tendencia vertical hasta enlazar en la zona media del vaso, con un baquetón de sección apuntada algo descendente.

41. Fragmento de borde y pared de forma Drag. 44 (fig. 13, n. ${ }^{\circ} 6$ ). Barniz ocre oro tostado mate (R-35) y pasta tierra siena tostada ( $\mathrm{N}-47)$ de fractura irregular. Conserva el perfil completo, a escepción de la base. El primer tramo de pared, presenta un perfil algo abombado, interrumpido por un baquetón moldurado, de sección cuadrangular y trayectoria algo descendente.

42. Fragmento de forma Hispánica 7 (fig. 13, n. ${ }^{\circ}$ ). Barniz tierra siena brillante (S-37) y pasta ocre carne ( $N$-45) con desgrasantes finos amarillentos y fractura regular. Dada la escasa porción conservada, resulta imposible determinar su conexión o no con los ejemplares gienenses. No obstante, su perfil parece mantener similitudes con una de las piezas ilustradas por M. Roca (RocA 1976, fig. 21, n. ${ }^{\circ} 78$ ).

43. Fragmento de pared de forma Hispánica 14 (fig. 14, n. ${ }^{\circ}$ 2). Barniz tierra siena brillante (S-39) aplicado únicamente en la superficie externa y pasta tierra siena tostada $(\mathrm{N}-47)$ con desgrasantes finos amarillentos y fractura regular. Presenta perfil de convexidad acentuada. Conserva una banda con decoración burilada, limitada por una acanaladura. Una pieza similar se encuentra presente en el estrato IV de Pamplona (MEzQuiRIz 1956, 157, fig. 70, n. ${ }^{\circ} 6$ ). Más recientemente, esta forma ha podido ser identificada en Andújar en un contexto datable en el siglo I d.C. (MEZQUIRIZ 1985, 147, lám. XXIX, n. ${ }^{\circ} 1$ ).

\section{Formas decoradas}

44. Fragmento de borde de forma Drag. 37 (fig. 14, n. ${ }^{\circ}$ ). Barniz tierra siena mate (R-39) y pasta tierra siena tostada (N-47) de fractura irregular. Presenta borde vertical provisto de labio de sección redondeada.

45. Fragmento de borde y pared de forma Drag. 37 (fig. 14, n. ${ }^{\circ} 3$ ). Barniz tierra siena brillante (S-39) y pasta ocre carne (N-45) con desgrasantes finos amarillentos. Conserva una mínima parte de la primera zona decorativa, en la que puede reconocerse una sucesión de motivos circulares segmentados, con elementos verticales de separación. Este último, parece estar constituido por dos líneas onduladas paralelas, rematadas en ambos extremos por sendas rosetas, similares a las documentadas en Andújar sobre forma 37 (RocA 1976, fig. 54, n. ${ }^{\circ} 601$ ).

46. Fragmento de borde y pared de forma Drag. 37 (fig. 14, n. ${ }^{\circ} 4$ ). Barniz tierra siena brillante (R-39) y pasta ocre carne ( $N-45)$ con desgra- 

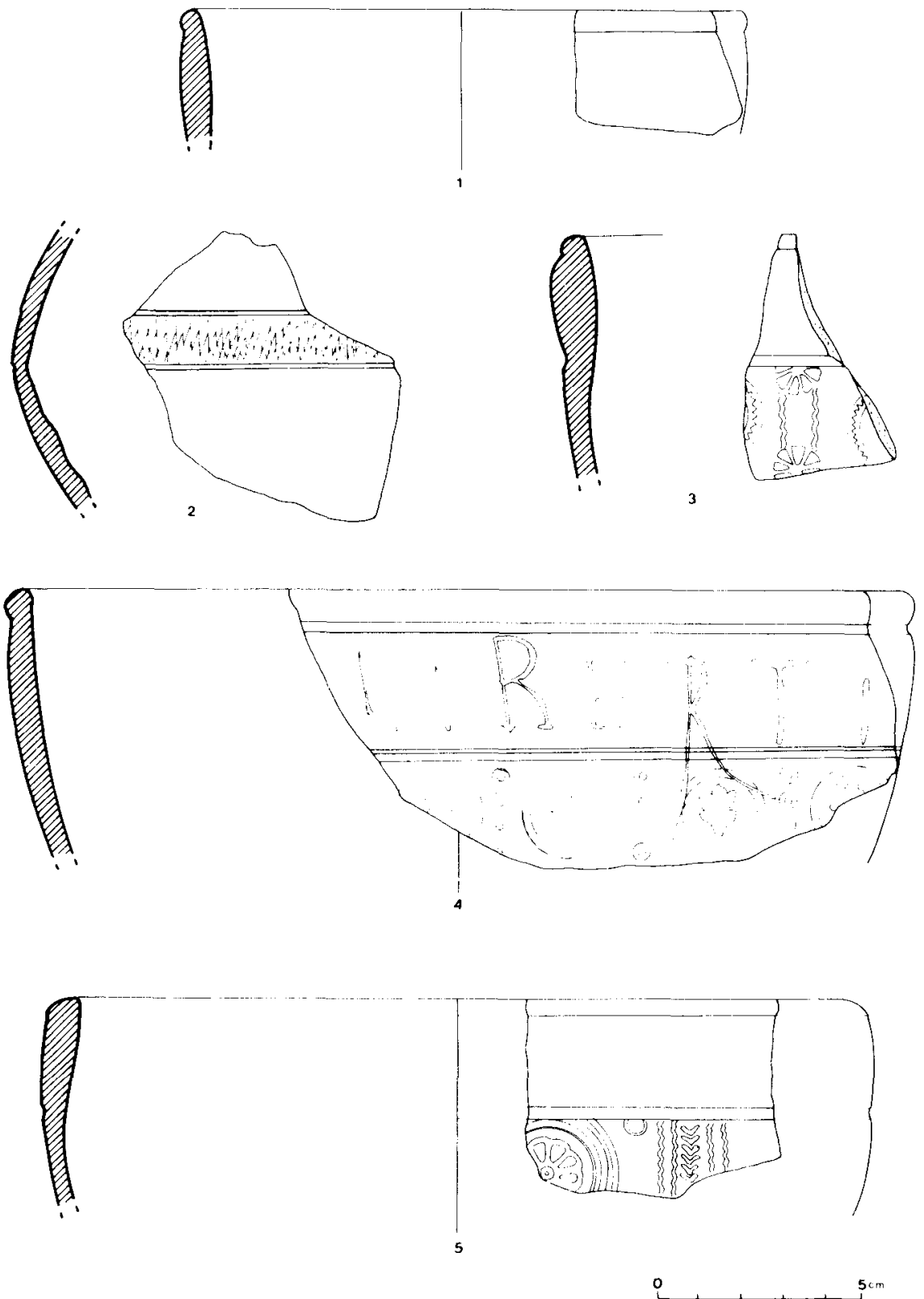

$5 \mathrm{~cm}$

Fig. 14. 
santes finos amarillentos. En la zona lisa inmediata al borde, conserva un grafito completo: LIBERTI. El primer espacio decorativo, se encuentra separado del anterior mediante dos molduras. Presenta una sintaxis ornamental constituida por elementos circulares con punzón vegetal inscrito y separados por motivos verticales, compuestos por hileras de pequeños círculos. Vegetales semejantes, aunque más elaborados, han sido documentados en Andújar sobre forma Drag. 37 (MAYET 1984, II, lám. XLVIIII, n. ${ }^{\text {os }}$ 139-140) y Conímbriga, en la misma forma (DELGADo et alii 1975, lám. XLI, n. ${ }^{\circ} 114$ ).

47. Fragmento de borde y pared de vaso (fig. 14, n. ${ }^{\circ} 5$ ). Barniz tierra siena brillante (R-39) y pasta tierra siena tostada con desgrasantes finos amarillentos. Conserva restos de la primera zona decorativa del vaso, de sintaxis metopada. Resulta visible un motivo circular incompleto, constituido por tres círculos concéntricos de línea lisa con roseta inscrita, así como un elemento separador de metopas, integrado por dos líneas onduladas a ambos lados de una hilera central de angulaciones.

Morfológicamente, la tipología del borde resulta similar a una de las piezas de Andújar estudiada por M. Roca, como correspondiente a la forma Drag. 29 (Roca 1976, fig. 23, ad. 3). El mismo ejemplar, fue incluido posteriormente por MAYET en la forma Drag. 37 (MAYET 1984, II, lám. XL, n. ${ }^{\circ}$ 198). A tenor de las diferencias planteadas por la clasificación de este perfil y ante la ausencia, en nuestro caso, de gran parte de la pared y la base, parece oportuno considerar nuestra pieza como un tipo intermedio entre las variedades de borde sencillo y almendrado de la forma Drag. 37.

Por lo que respecta a los motivos decorativos, rosetas similares han sido identificadas en Andújar sobre forma Drag. 37 (MAYET 1984, II, lám. XLV, n. ${ }^{\circ} 60$; Sotomayor 1977, lám. 29, n. ${ }^{\circ} 245$ ).

48. Fragmentos de borde y pared de forma Drag. 37 (fig. 15, n. ${ }^{\circ}$ 1). Barniz tierra siena brillante (S-39) y pasta tierra siena tostada (N-47) con desgrasantes finos amarillentos y fractura regular. Tipológicamente mantiene rasgos formales muy próximos al ejemplar precedente. Conserva restos de la primera zona decorativa, integrada según parece, por una sucesión alternante de motivos circulares y elementos verticales de separación. Los primeros están constituidos por dos círculos concéntricos de línea sogueada, con punzón inscrito de difícil identificación. Los motivos separativos poseen un remate superior de carácter vegetal.

49. Fragmento de base de posible forma Drag. 37 (fig. 15, n. ${ }^{\circ}$ ). Barniz tierra siena brillante (S-39) y pasta tierra siena tostada (N-47) con desgrasantes finos amarillentos y fractura regular. Conserva evidencias de 

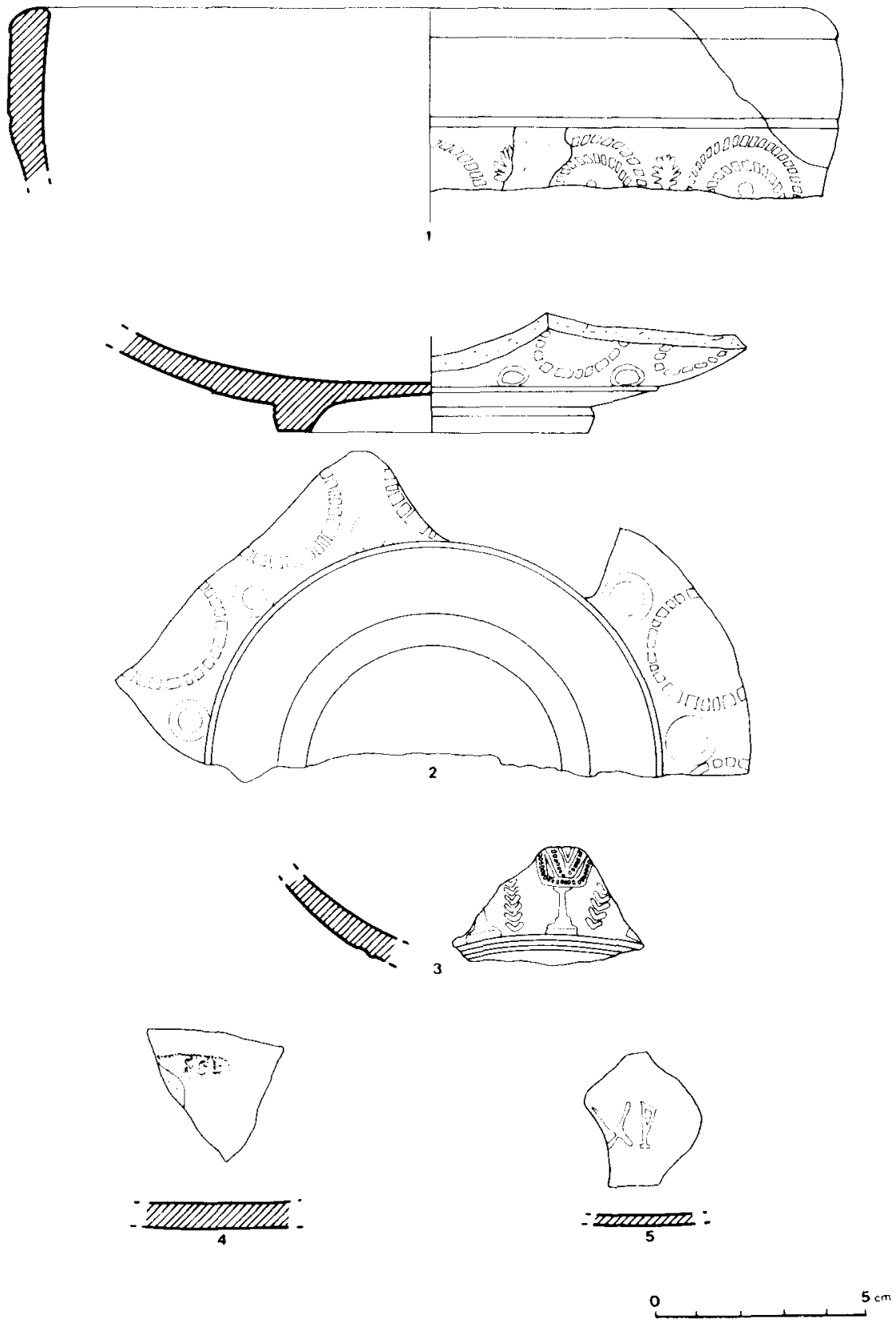

Fig. 15. 
la zona decorativa inferior del vaso, provista de una sucesión de círculos segmentados y pequeños círculos ubicados en los ángulos creados por los primeros.

50. Fragmento de pared de posible forma Drag. 37 (fig. 15, n. ${ }^{\circ}$ ). Barniz tierra siena brillante (S-39) y pasta ocre carne $(\mathrm{N}-45)$ con desgrasantes finos amarillentos y fractura regular. Conserva escasas evidencias de la decoración original. Puede reconocerse un motivo similar a un ara, coronado por elementos de difícil identificación y flanqueado por sendas hileras verticales de angulaciones. No hemos hallado motivos idénticos, aunque el aquí ilustrado debe responder a la idea figurativa presente en Andújar sobre forma Drag. 37 (ROCA 1976, fig. 51, n. ${ }^{\circ} 464$; MAYET 1984, II, lám. XLVII, n. ${ }^{\circ} 116$; SOTOMAYOR 1977, fig. 15, n. ${ }^{\circ} 115$ ).

51. Fragmento de fondo de forma indeterminada (fig. 15, n. ${ }^{\circ} 4$ ). Barniz tierra siena brillante (S-39) y pasta tierra siena natural clara (N-37). Conserva una marca de oficina incompleta, inscrita en cartela rectangular. Puede leerse: ... (O)F. C.L... Este alfarero, ligado al centro de producción de Andújar (MAYET 1984, I, 129, n. ${ }^{\text {s }}$ 138-144), se encuentra documentado, al margen del propio yacimiento giennense, en Banasa (BouBE 1965, 237238, n. ${ }^{\text {os }}$ 333-335) y Sala (Drounor 1966, 152, n. ${ }^{\circ} 15$ ).

52. Fragmento de fondo de forma indeterminada, recortado a modo de ficha de juego (fig. $15, n .{ }^{\circ}$ ). Barniz tierra siena brillante (S-39) y pasta tierra siena natural clara (N-37) con desgrasantes amarillentos. Conserva restos de un grafito, en el que puede reconocerse ...XP.

TSH procedente de los alfares riojanos

\section{Formas lisas}

1. Fragmento de borde y pared de forma Ritt. 8 (fig. 16, n. ${ }^{0}$ ). Barniz rojo inglés brillante (R-20) y pasta rojo inglés (R-19) con desgrasantes finos blancuzcos. Presenta borde sencillo, de sección redondeada e incurvado hacia el interior.

2. Fragmento de borde y pared de forma Ritt. 8 (fig. 16, n. ${ }^{\circ}$ ). Barniz rojo inglés brillante (R-20) y pasta rojo inglés (R-19) con desgrasantes finos blancuzcos y fractura regular. Presenta borde vertical, marcado in teriormente por una ranura.

3. Fragmento de base de posible forma Drag. 27 (fig. 16, n. ${ }^{\circ} 3$ ). Barniz rojo inglés brillante (R-20) y pasta rojo inglés (R-19) con desgrasantes finos blancuzcos y fractura regular. Presenta pie muy elevado, de sección triangular, provisto de moldura en el punto de unión con el fondo externo. 

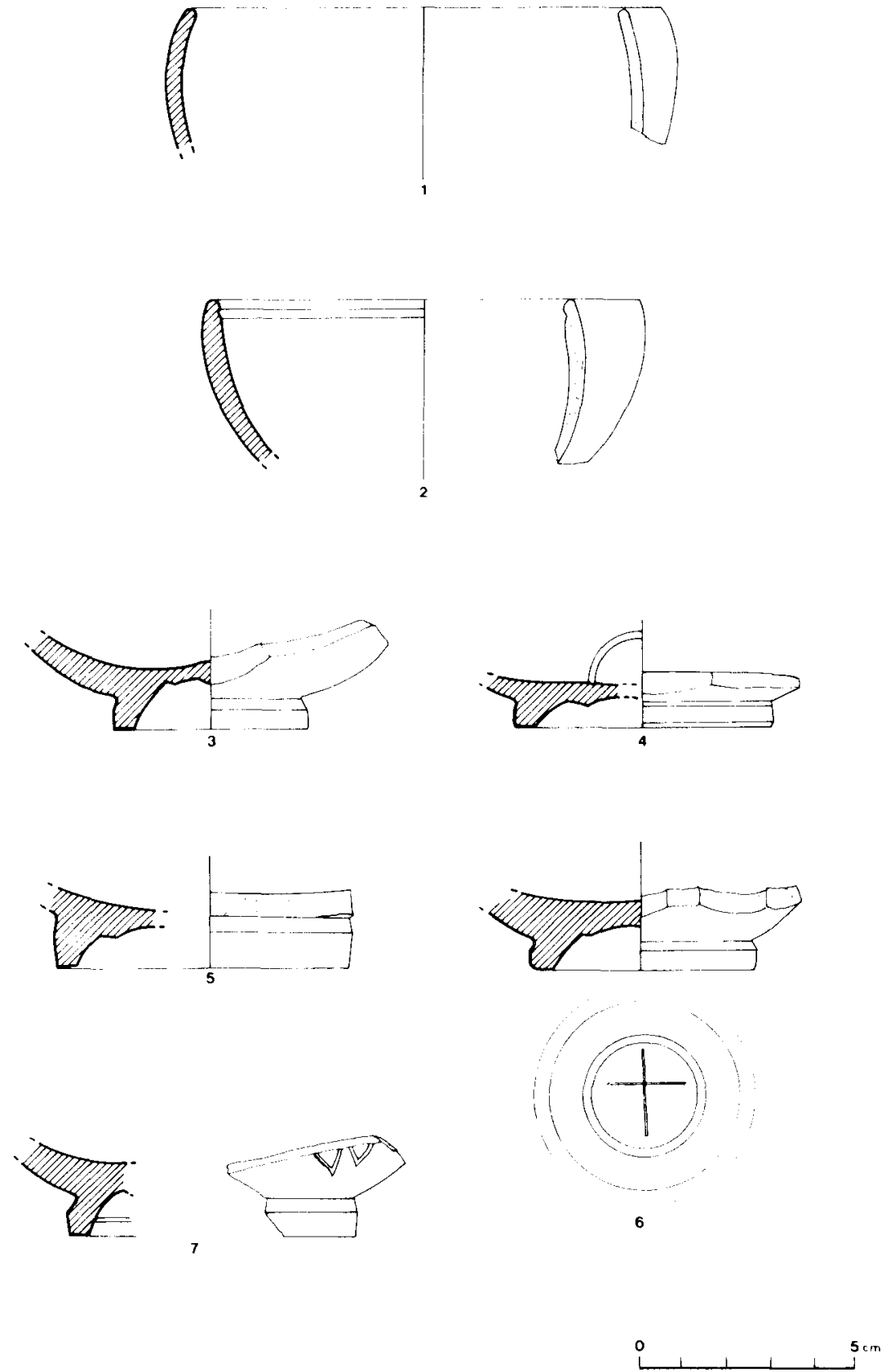

Fig. 16. 
4. Fragmento de base de posible forma Draq. 27 (fig. 16, n. ${ }^{\circ}$ 4). Barniz rojo inglés brillante (R-20) y pasta rojo inglés claro (M-15) con desgrasantes finos blancuzcos y fractura regular. Presenta pie elevado, de sección triangular y moldura hispánica en el fondo externo.

5. Fragmento de base de posible forma Drag. 27 (fig. 16, n. ${ }^{0}$ 5). Barniz rojo inglés brillante (R-20) y pasta rojo inglés claro (M-15) con desgrasantes finos blancuzcos y fractura regular. Conserva pie elevado, de sección triangular y moldura hispánica en el fondo externo.

6. Fragmento de base de posible forma Drag. 27 (fig. 16, n. ${ }^{\circ} 6$ ). Barniz rojo inglés brillante (P-19) y pasta rojo inglés claro ( $\mathrm{N}-20)$ con desgrasantes finos blancuzcos. Presenta pie alto y moldura en el fondo externo, donde resulta visible un grafito cruciforme.

7. Fragmento de base de posible forma Drag. 27 (fig. 16, n. ${ }^{\circ}$ ). Barniz rojo inglés brillante $(P-19)$ y pasta tierra verde tostada $(\mathrm{N}-25)$ con desgrasantes finos blancuzcos. Presenta características análogas a las apuntadas en los ejemplares anteriores. Aparecen restos de un grafito de imposible identificación, en la pared externa.

8. Fragmento de borde y pared de forma Drag. 35 (fig. 17, n. ${ }^{\circ} 1$ ). Barniz rojo inglés (R-20) brillante en la superficie externa y mate en el interior y pasta rojo inglés claro (M-15). Presenta borde vuelto de trayectoria descendente, provisto de ranura interna. Conserva restos de decoración a barbotina.

9. Fragmento de borde y pared de forma Drag. 35 (fig. 17, n. ${ }^{\circ}$ ). Barniz tierra siena brillante (R-39) y pasta tierra siena natural clara $(\mathrm{N}-39)$ con desgrasantes finos blancuzcos. Presenta borde vuelto, de trayectoria vertical, con decoración de hojas de agua a la barbotina. La pared desarrolla un movimiento hemiesférico bastante marcado.

10. Fragmento de borde y pared de forma Drag. 35 (fig. 17, n. ${ }^{\circ} 3$ ). Barniz rojo inglés brillante (R-19) y pasta tierra verde tostada $(\mathrm{N}-25)$ con desgrasantes finos blancuzcos y fractura irregular. Presenta borde vuelto descendente, con restos de decoración a barbotina.

11. Fragmento de borde y pared de forma Drag. 35 (fig. 17, n. ${ }^{\circ} 5$ ). Barniz rojo inglés brillante (R-20) y pasta tierra verde tostada $(\mathrm{N}-25)$ con desgrasantes finos blancuzcos. Presenta borde vuelto y descendente, con ranura interna. La zona conservada no ofrece evidencias de decoración a barbotina.

12. Fragmento de borde y pared de forma Drag. 35 (fig. 17, $n .{ }^{\circ} 4$ ). Barniz rojo inglés brillante $(\mathrm{P}-20)$ y pasta rojo inglés claro $(\mathrm{N}-19)$ de 


\section{4}
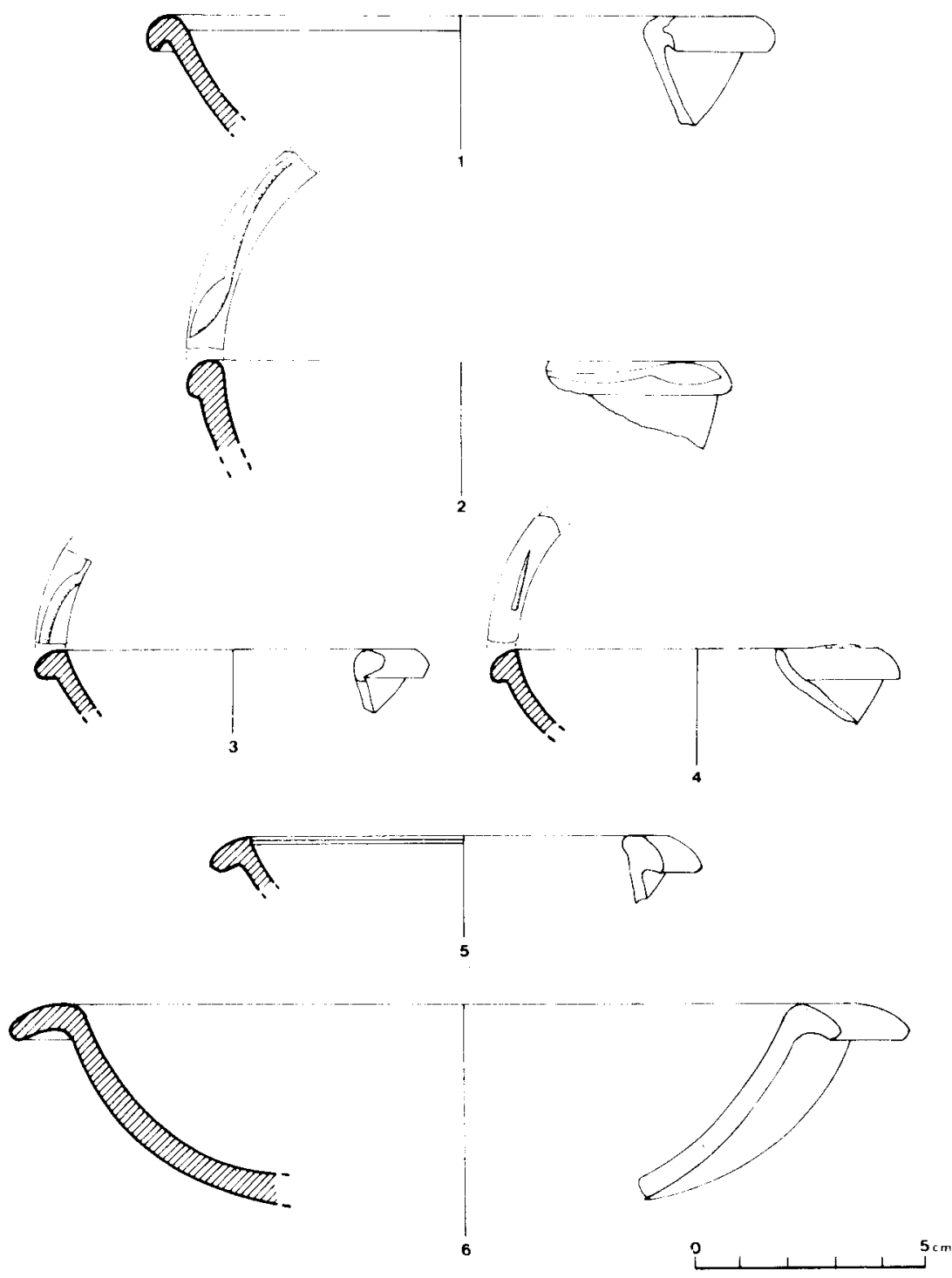

Fig. 17 . 
fractura irregular. Presenta borde vuelto descendente, con restos de decoración a barbotina. La pared manifiesta marcada tendencia hemiesférica.

13. Fragmento de borde y pared de forma Drag. 36 (fig. 17, n. ${ }^{\circ}$ ). Barniz rojo inglés mate ( $P-20)$ y pasta rojo inglés claro ( $M-15)$ de fractura regular. Presenta borde vuelto, algo descendente y de sección alargada.

14. Fragmento de borde de forma Drag. 36 (fig. 18, n. ${ }^{\circ}$ ). Barniz rojo ingles brillante ( $P$-19) y pasta tierra siena natural clara (N-39) de fractura irregular. Conserva borde vuelto, descendente, de sección alargada.

15. Fragmento de borde de forma Drag. 36 (fig. 18, n. ${ }^{\circ}$ ). Barniz tierra siena brillante (R-39) y pasta tierra siena tostada (M-37) con desgrasantes finos. Presente borde vuelto, de trayectoria horizontal con ranura interna y provisto de hoja de agua a la barbotina.

16. Fragmento de borde y pared de forma Drag. 36 (fig. 18, n. ${ }^{\circ}$ ). Barniz rojo inglés mate ( $\mathrm{R}-20)$ y pasta tierra siena tostada (M-37) de fractura regular. Presenta borde vuelto, algo descendente, con ranura interna. No conversa evidencias de decoración a barbotina.

17. Fragmento de borde de forma Drag. 36 (fig. 18, n. ${ }^{\circ}$ ). Barniz rojo inglés brillante $(P-19)$ y pasta rojo inglés claro $(\mathrm{N}-20)$ de fractura regular. Conserva borde vuelto, de trayectoria descendente y provisto de decoración a barbotina.

18. Fragmento de borde de forma Drag. 36 (fig. 18, n. ${ }^{\circ}$ ). Barniz tierra siena brillante (R-39) y pasta tierra siena tostada (M-39) con desgrasantes finos y fractura regular. Presenta borde vuelto, muy descendente, con decoración de hoja de agua a la barbotina.

19. Fragmento de borde y pared de forma Drag. 36 (fig. 18, n. ${ }^{\circ}$ ). Barniz tierra siena brilante (R-37) y pasta tierra siena tostada ( $\mathrm{M}-37$ ) con desgrasantes finos blancuzcos. Presenta borde vuelto, de trayectoria casi horizontal, sin evidencias de decoración a barbotina.

20. Fragmento de borde y cuello de forma indeterminada (fig. $19, \mathrm{n} .^{\circ}$ 1). Barniz tierra siena brillante (R-39) y pasta tierra siena natural clara ( $\mathrm{N}$ 37 ) con desgrasantes finos. Presenta borde con concavidad interna, provisto de una ranura.

21. Fragmento de borde y cuello de botella (fig. 19, $n .^{\circ} 2$ ). Barniz rojo inglés brillante (R-20) y pasta tierra siena tostada (M-37) con desgrasantes finos blancuzcos y fractura regular. Presenta borde con concavidad interna marcada por una ranura. La articulación con el cuello se produce mediante un fuerte movimiento cóncavo. Conserva restos de un asa. 

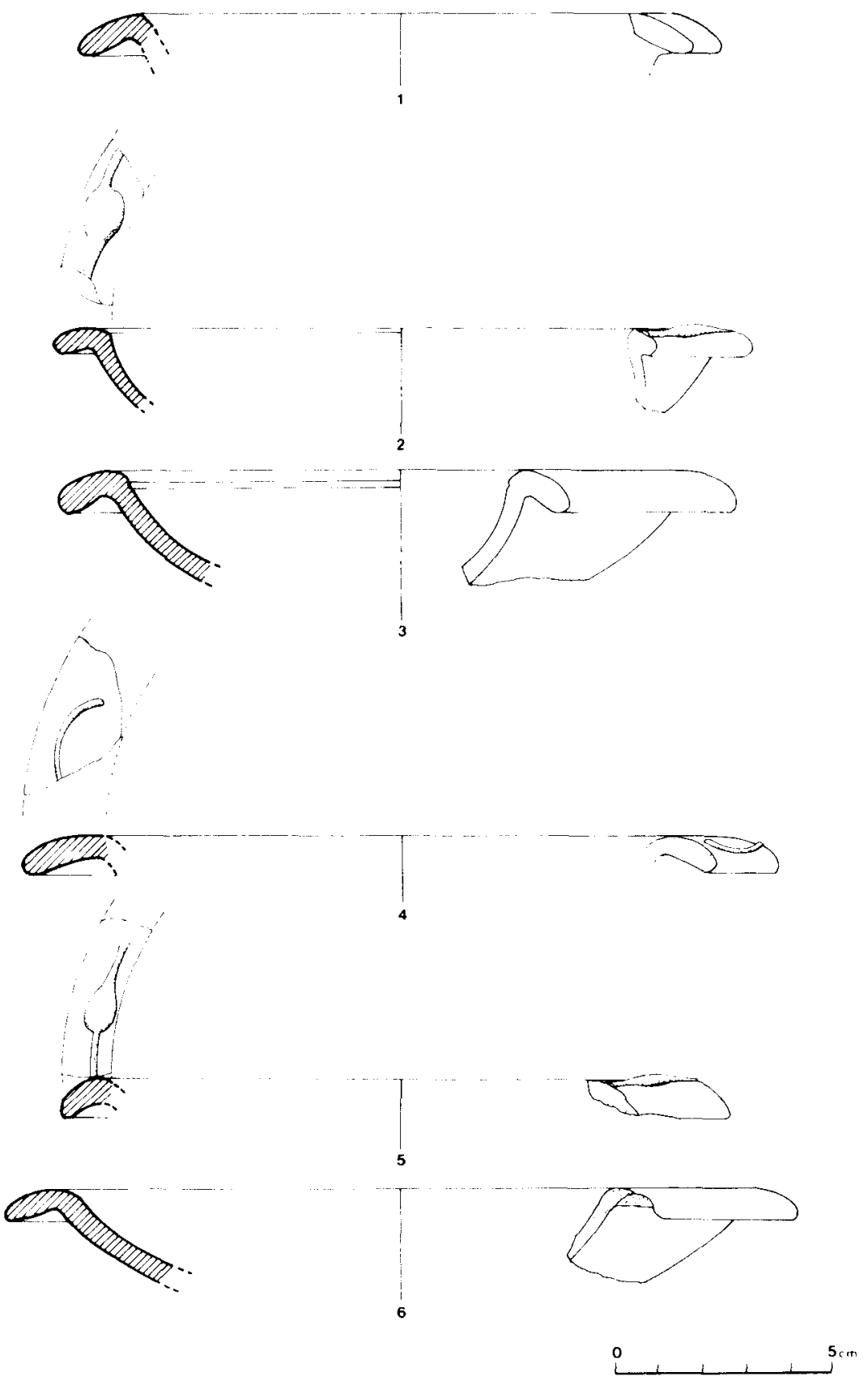

Fig. 18. 
22. Fragmento de esa correspondiente a un vaso de forma indeterminada (fig. $19, n .{ }^{\circ}$ ). Barniz rojo inglés brillante (R-19) y pasta tierra verde tostada $(M-47)$.

\section{Formas decoradas}

23. Fragmento de borde de forma Drag. 29 (fig. 19, n. ${ }^{\circ} 4$ ). Barniz tierra siena (R-39) y pasta tierra siena tostada $(M-37)$ con desgrasantes finos blancuzcos y fractura regular. Presenta borde exvasado, provisto de labio de sección redondeada. Su exigüedad impide reconocer motivos decorativos pertenecientes al primer espacio ornamental del vaso.

24. Fragmento de borde de forma Drag. 29 (fig. 19, n. ${ }^{\circ}$ ). Barniz rojo inglés brillante $(P-20)$ y pasta tierra siena tostada $(M-37)$ con desgrasantes finos. Presenta borde muy exvasado, prácticamente oblícuo.

25. Fragmento de borde y pared de forma Drag. 29 (fig. 19, n. ${ }^{\circ} 6$ ). Barniz tierra siena tostada clara brillante $(\mathrm{N}-35)$ y pasta tierra siena tostada (M-37) con desgrasantes finos blancuzcos. Conserva evidencias de la primera zona decorativa, en la que únicamente puede reconocerse parte de un motivo decorativo circular de línea lisa.

26. Fragmento de borde y pared de forma Drag. 29 (fig. 19, n. ${ }^{\circ}$ ). Barniz rojo inglés mate (R-20) y pasta tierra verde tostada (M-47) con desgrasantes finos. No conserva evidencias de su decoración original.

27. Fragmento de borde y pared de forma Drag. 29 (fig. 20, n. ${ }^{\circ} 1$ ). Barniz tierra siena brillante (R-39) y pasta tierra verde tostada $(\mathrm{N}-29)$ con desgrasantes finos blancuzcos y fractura regular. Conserva restos de dos de los espacios ornamentales del vaso, aislados por dos finas molduras. En el superior, se aprecia parte de una composición metopada, en la que resultan visibles cuatro líneas onduladas, como elemento separador de paneles, y dos punzones vegetales repetidos. Motivos trifoliados similares a éstos, han sido documentados en Mérida sobre Drag. 29 (MezQIRIz 1985, lám. XLII) y Tricio (GARABITo 1978, 521, tab. 17, n. ${ }^{\circ} 18$ ). Este elemento vegetal resulta especialmente frecuente en el área de difusión de los productos tricienses (MAYET 1984, II, lám. CLXV).

La segunda zona debió estar constituida por series de círculos alternantes con motivos verticales de separación. Los elementos circulares se hallan compuestos por círculo simple de línea segmentada, con roseta eneapétala inscrita, similar a las que figuran en Mérida sobre un vaso de forma Drag. 29 (Mezquiriz 1961, II, lám. 94, n. ${ }^{\circ}$ 1555) y Conimbriga en la misma forma (DELGADo et alii 1975, lám. XXXIV, n. ${ }^{\circ}$ ). El motivo separador 

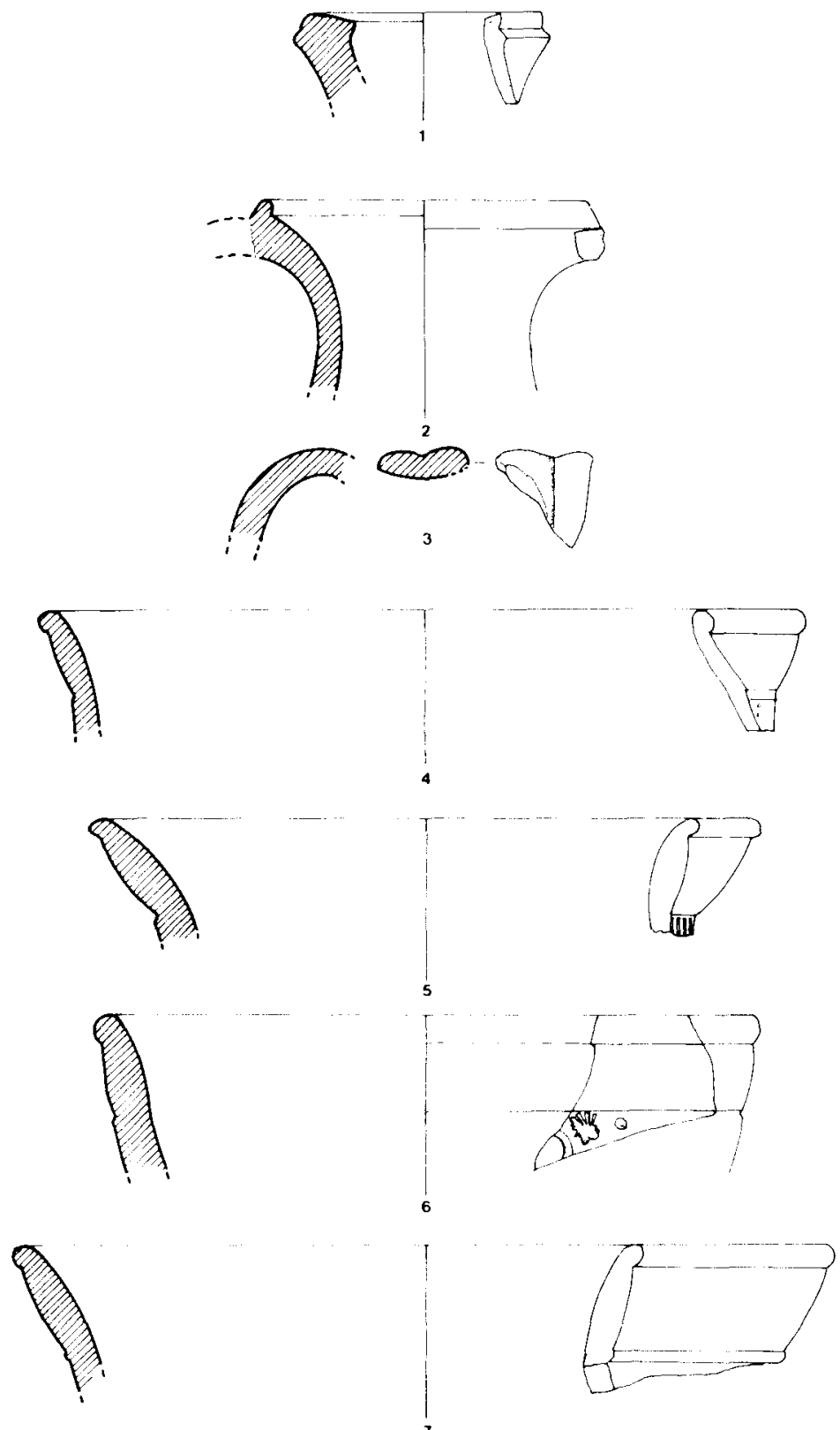

0 $5 \mathrm{~cm}$

Fig. 19. 
se encuentra formado por dos líneas onduladas con remate foliar, a ambos lados de una hilera vertical de perlitas.

28. Fragmento de borde y pared de forma Drag. 29 (fig. 20, n. ${ }^{2}$ ). Barniz tierra siena brillante (R-39) y pasta tierra siena tostada (M-37). Presenta restos de la primera zona decorativa del vaso, de sintaxis metopada. El panel de la izquierda, originariamente subdividido, tal y como indica la presencia de dos ángulos en disposición horizontal, cuenta con tres motivos foliáceos. A continuación, aparece el elemento separador de metopas, constituido por cinco líneas onduladas, y una porción muy reducida del siguiente panel, igualmente subdividido. En este último, resultan visibles dos motivos vegetales idénticos. Elementos foliáceos muy similares a los primeros, están presentes en Numancia sobre forma Drag. 37, en composición de friso continuo (ROMERo 1985, fig. 42, n. ${ }^{\circ} 385$ ) y en forma 29 y $29-37$ con idéntica sintaxis (Idem, fig. 20, n. ${ }^{\circ} 158 ;$ fig. 27, n. ${ }^{\circ} 262$ ). Romero considera estos tres ejemplares, obra de un mismo taller (Idem, $80, n .{ }^{\circ} 158$ ), al que posiblemente corresponderían también, al menos tres piezas halladas en Tiermes (ARGENTE et alii 1980, figs. 12,13 y 16, n. ${ }^{\text {os }}$ 183,191 y 120).

29. Fragmento de pared de forma Drag. 29 (fig. 20, n. ${ }^{\circ}$ ). Barniz tierra siena y pasta tierra verde tostada $(\mathrm{N}-29)$ de fractura regular. Conserva una parte muy exigua de una de las zonas decorativas del vaso, aislada de la inmediatamente inferior por dos molduras. Puede reconocerse un punzón zoomorfo pasante a la izquierda, con la cabeza vuelta hacia la derecha. Resulta muy probable que pueda identificarse con una pantera, de ejecución prácticamente idéntica a las que figuran sobre un vaso de forma Drag. 29, procedente de Numancia (Romero 1985, fig. 19, n. ${ }^{\circ} 138$ ). El mismo punzón de felino, ha sido documentado, también sobre forma 29, en Bezares (GARABITO 1978, tab. 10, no 5; tab. $11, n{ }^{\text {os }} 10$ y 18) y en Tricio (Idem, tab. 12, n. ${ }^{\circ} 22$ ). La difusión proporcionada por Mezquiriz para este motivo (MEZQuIRIz 1961, II, lám. 70, n. ${ }^{05}$ 644-650), se ha visto incrementada notablemente mediante la publicación de nuevos ejemplares (MAÑANES 1976, fig. 6, n. ${ }^{\circ}$ 22; Burillo 1977, fig. 13, n. ${ }^{\circ}$ 2; Martín Serres 1970, fig. 38 , n. ${ }^{\circ} 9$, entre otros).

30. Fragmento de pared de forma Drag. 29 (fig. 20, n. ${ }^{\circ}$ 4). Barniz rojo inglés brillante $(P-20)$ y pasta tierra siena tostada (M-37) con desgrasantes finos blancuzcos. Conserva evidencias de dos de las zonas decorativas del vaso, aisladas por sendas molduras. En la superior, de sintaxis metopada, resulta visible parte del elemento separador y de uno de los paneles, en el que figura un mismo punzón zoomorfo, dispuesto en doble hilera vertical. Motivos prácticamente idénticos y un esquema muy similar, han sido documentados en Uxama (Garcia GUINEA 1959, figs. 26 y 21), 

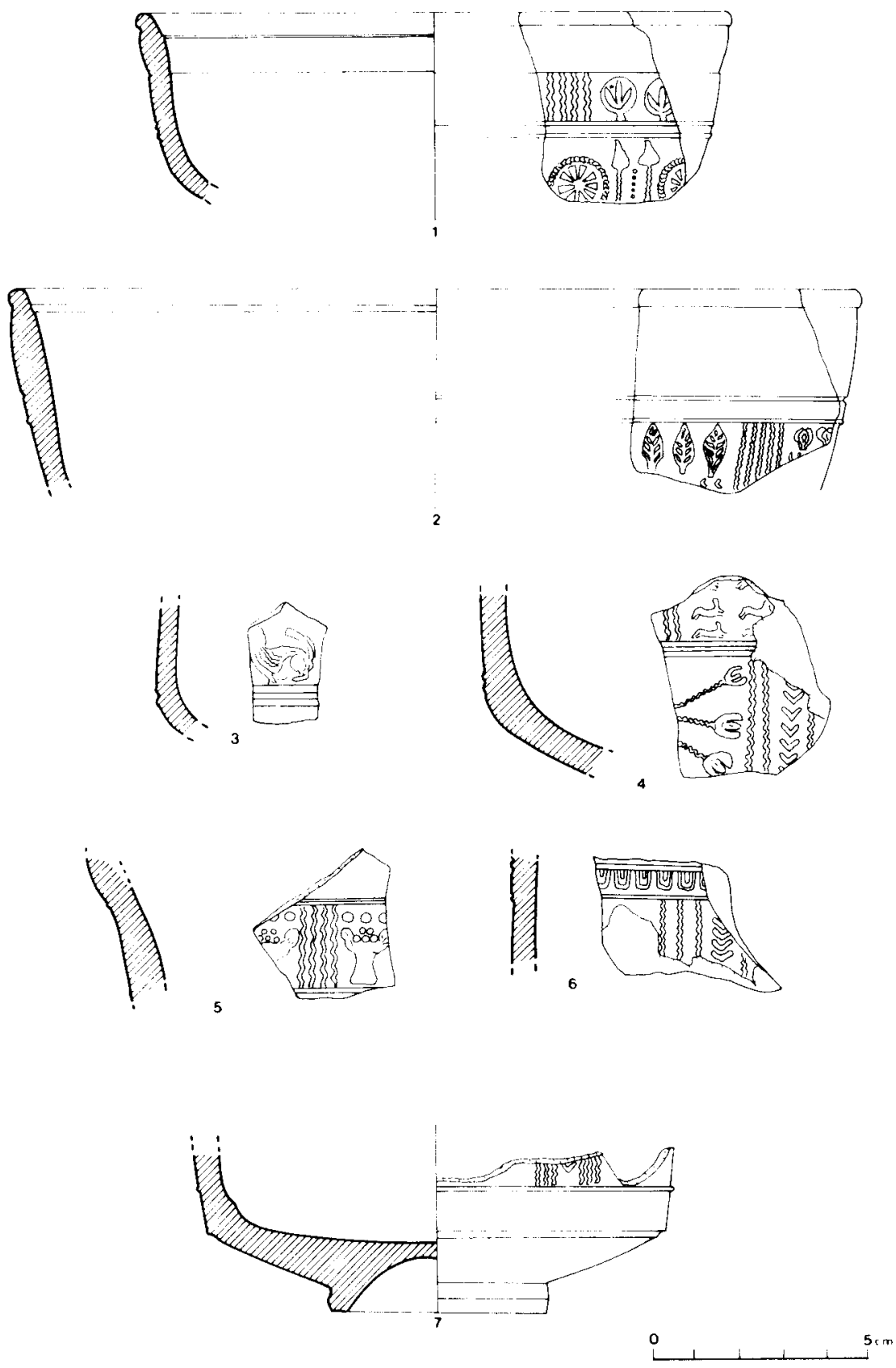

Fig. 20. 
Tiermes (ARgente et alii 1980, fig. 8, n. ${ }^{\circ} 25$ ) y Numancia (Romero 1985, fig. $40, n .{ }^{\circ} 363$ y 364 ).

En la zona inferior, también de sintaxis metopada, puede reconocerse parte de un motivo cruciforme y del elemento separador de paneles, constituido por dos líneas onduladas a ambos lados de una hilera central de ángulos. El remate vegetal que figura en los brazos de la cruz de $S$. Andrés, parece similar al documentado en Tricio (GARABITO 1978, 361, fig. 89, n. ${ }^{\circ}$ 127 y especialmente n. ${ }^{\circ} 128$ ).

31. Fragmento de pared de forma Drag. 29 (fig. 20, n. ${ }^{\circ}$ 5). Barniz rojo inglés brillante (P-20) y pasta tierra siena tostada (M-37) con desgrasantes finos. Presenta una escasa porción de la zona ornamental superior, de sintaxis metopada. Puede reconocerse con claridad, el elemento de separación, constituido por líneas onduladas, así como el inicio de dos de los paneles, en los que figura un mismo motivo de dudosa interpretación. Pensamos que puede tratarse de vasos cerámicos provistos de dos asas. No ha sido posible hallar representaciones análogas, aunque desde el punto de vista figurativo, este motivo resulta próximo a los documentos en Conímbriga sobre forma Drag. 37 (DELGado et alii 1975, lám. XLI, n. ${ }^{\circ s} 126$ y 127).

32. Fragmento de base y pared de forma Drag. 30 (fig. 20, n. ${ }^{\circ}$ ). Barniz rojo inglés brillante (R-20) y pasta rojo muy pálido (L-29). Presenta pie elevado, de sección triangular y moldura en cuarto de círculo poco acusada en el punto de articulación entre la pared y el fondo interno. Conserva mínima evidencia de la zona decorativa inferior, de la que únicamente puede afirmarse su carácter metopado, con elemento de separación constituido por tres líneas onduladas a ambos lados de una hilera central de ángulos.

33. Fragmento de pared de forma Drag. 30 (fig. 20, n. ${ }^{\circ} 6$ ). Barniz tierra siena brillante (R-39) y pasta rojo muy pálido (L-29). Conserva parte de la zona decorativa más próxima al borde del vaso. En ella, resulta visible un friso inicial de ovas con doble arco, así como restos de un espacio metopado, del que resta un motivo de separación, constituido por tres líneas onduladas a ambos lados de una hilera central de ángulos.

34. Dos fragmentos de borde y pared de forma Drag. 37 (fig. 21 , n. ${ }^{\circ}$ ). Barniz tierra siena brillante (R-39) y pasta tierra siena tostada (M37). Ha sido posible proceder a la reconstrucción de una parte de la primera zona decorativa del vaso. Sin duda, responde a una sintaxis metopada, en la que resulta visible de izquierda a derecha, parte de un panel, limitado superior e inferiormente por una hilera horizontal de angulaciones enmarcada por pequeños círculos. A continuación, puede reconocerse el 
elemento separador de metopas, constituido por tres líneas onduladas, así como el siguiente panel, ocupado enteramente por cinco hileras verticales de triángulos invertidos o quizá, motivos vegetales muy simplificados, sin paralelos en los repertorios conocidos. Seguidamente, el mismo elemento de separación y restos de un posible motivo cruciforme.

La segunda zona, se encuentra aislada de la anterior mediante una moldura. Presenta también sintaxis metopada, con idéntico elemento separativo. En el panel central, resulta visible un tema cruciforme con tres elementos decorativos, convergentes hacia el centro de la cruz y emplazados en los ángulos creados por los brazos. Destacamos la originalidad del conjunto, que carece de paralelos en el marco de la TSH publicada. Los dos restantes paneles visibles, debieron contar con motivos circulares, apenas conservados.

35. Fragmento de pared de forma Drag. 37 (fig. 21, n. ${ }^{\circ}$ ). Barniz tierra siena brillante (R-39) y pasta tierra siena tostada. Conserva parte de una zona ornamental del vaso, en la que puede reconocerse una sucesión de círculos concéntricos, de línea segmentada el exterior y lisa el interior, en alternancia con elementos verticales de separación. Estos últimos, están constituidos por una línea ondulada con remates trifoliados. Motivos similares a éstos han sido identificados en zonashabitualmente adscritas al área de difusión de los productos de Tritium Magallum (MAYET 1984, II, lám. CXXXIX, n. ${ }^{\circ 5}$ 298-308). Destacamos por su especial semejanza, el $n{ }^{\circ} 298$, relacionado con un baso procedente de Barcelona, en forma Drag. 37 de borde almendrado.

36. Fragmento de pared de forma Drag. 37 (fig. 21, n. ${ }^{\circ}$ ). Barniz tierra siena brillante (R-39) y pasta tierra siena tostada (M-37) con desgrasantes finos blancuzcos. Presenta restos de uno de los espacios decorativos, de sintaxis metopada. Resulta visible parte de uno de los paneles, en el que figura un motivo circular incompleto y un gallón coronado por un gallo pasante a la izquierda. Bajo el gallón, parece un pequeño círculo con botón central. El elemento separador de metopas está constituido por dos líneas onduladas a ambos lados de una hilera central de ángulos. Gallones similares al de nuestro fragmento, están constatados en Valeria (SANCHEZLAFUENTE 1985, 116 y 118, fig. 33, n. ${ }^{\circ}$ 101), Arenzana de Arriba (GARABITO 1978, 441-442, fig. 108, n. ${ }^{\circ}$ 19) y Mérida (MAYET 1984, II, lám. CXXXIII, n. ${ }^{\circ}$ 82). Por lo que respecta al ave, motivos semejantes figuran en un vaso de Numancia (MAYET 1984, II, lám. CLXXI, n. ${ }^{\circ} 1490$ ) y en Valeria (SANCHEZLAFUENTE 1985,114 , fig. $32, n .{ }^{\circ} 8$ ), donde el motivo aparece asociado a un tema cruciforme.

37. Fragmento de borde de forma Drag. 37 de labio almendrado (fig. 21, n. $\left.^{\circ} 5\right)$. Barniz tierra siena mate (R-39) y pasta rosa $(M-20)$ con des- 

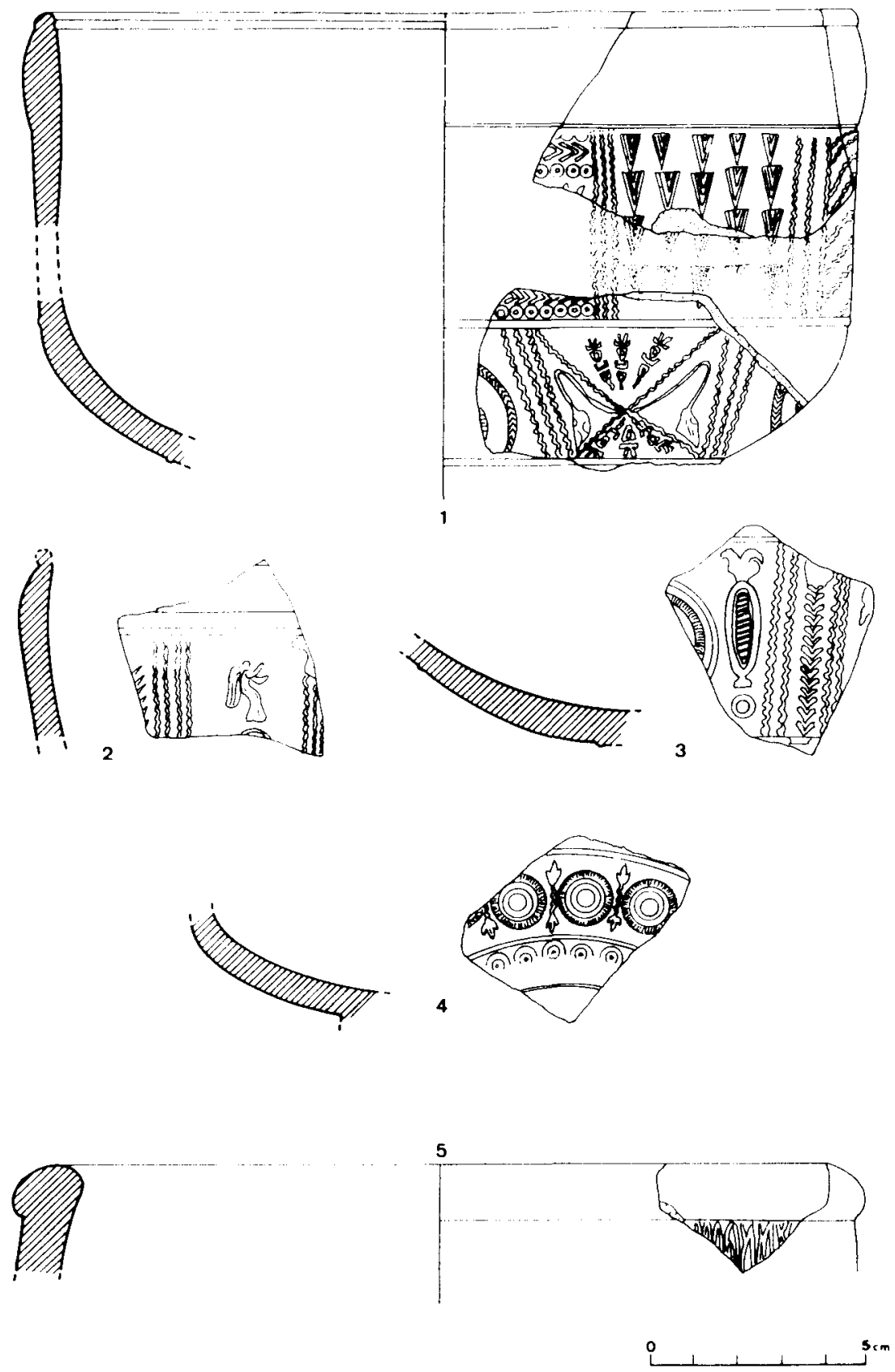

Fig. 21. 
grasantes finos blancuzcos. Conserva únicamente una exigua parte de la zona próxima al labio, con restos de decoración burilada.

38. Fragmento de pared de posible forma Drag. 37 (fig. 21, n. ${ }^{\circ}$ 2). Barniz tierra siena brillante (R-39) y pasta tierra siena tostada (N-47). Conserva parte del primer espacio decorativo del vaso, de sintaxis metopada. EI único panel visible, contiene una figurilla de Victoria alada, sobre un pequeño círculo. Los elementos de separación de metopas debieron estar constituidos por cuatro líneas onduladas, a ambos lados de una hilera central de ángulos. Este tipo de representación de Victoria, se inscribe en el marco de una tendencia evolutiva, marcada por la miniaturización y esquematización de las Victorias portadoras de corona o cuerno de la abundancia (MAYET 1984, I, 92). La difusión de este motivo resulta especialmente abundante en el área de influencia de los productos tricienses

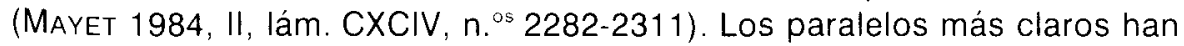
podido ser rastreados en Mérida (MAYET 1984, II, lám. CXCIV, n. ${ }^{\circ} 2292$ ), Numancia (MezQuiriz 1961, II, lám. 53, n. ${ }^{\circ}$ 157), Arenzana (GARABito 1978, 445-446, fig. 109, n. ${ }^{\circ} 36$ ), Bezares (/dem, 97, fig. 12, n. ${ }^{\circ} 81$ ), Tiermes (FERNANDez Martínez 1982, fig. $1, \mathrm{n}^{\circ}{ }^{\circ}$ ) y Valeria (SÁnchez-Lafuente 109, fig. $\left.30, n .{ }^{\circ} 63\right)$

\section{TSH PROCEDENTE DE OTROS ALFARES}

\section{Formas lisas}

1. Forma Drag. $24 / 25$ conservada prácticamente en su totalidad (fig. 22 , n. ${ }^{\circ}$ 1). Barniz tierra siena tostada mate (P-25) y pasta tierra verde tostada (N-25) con desgrasantes finos. Presenta borde vertical, desprovisto de labio. El baquetón que caracteriza la forma, ofrece sección redondeada y se encuentra situado aproximadamente en el punto medio de la altura del vaso. Conserva pie poco esbelto, de sección muy gruesa. La pasta cerámica con que está confeccionado el vaso, resulta fácilmente erosionable.

2. Fragmento de borde y pared de forma Drag. 27 (fig. 22, n. ${ }^{\circ}$ ). Barniz rojo inglés brillante (P-20) y pasta tierra siena natural clara (N-37) de fractura irregular. Presenta un cuarto de círculo superior, de curvatura escasamente acentuada y de proporciones sensiblemente mayores al inferior. Las cualidades físicas de la pasta resultan muy semejantes a las del ejemplar precedente.

3. Forma Drag. 27 conservada prácticamente en su totalidad (fig. 22, n. ${ }^{\circ}$ ). Barniz rojo inglés brillante $(\mathrm{P}-20)$ y pasta tierra verde tostada (M35) de fractura regular. Presenta borde desprovisto de labio y cuarto de 
círculo de curvatura más acentuada que en la pieza anterior. Conserva pie elevado y esbelto, de sección triangular. En el fondo interno se aprecia una marca de oficina, inscrita en cartela rectangular. Puede leerse ...PF. $\mathrm{Ha}$ sido posible localizar vasos firmados por C.P.F en Castulo y Tarragona, con grafía similar, aunque provistos en ambos casos, de interpunción (MAYET 1984, II, lám. CCX, n. ${ }^{o s} 154$ y 155). Mayet vincula tales productos con el área de Andújar, sin embargo, los rasgos físicos presentes en nuestro ejemplar, impiden su adscripción al citado centro.

\section{Formas decoradas}

4. Fragmentos de borde y pared de forma Drag. 37 (fig. $22, n .{ }^{\circ} 4$ ). Barniz rojo inglés ( $P$-20) y pasta tierra siena natural clara ( $N-37$ ) . Conserva parte de la primera zona decorativa del vaso, iniciada por un friso de rosetas de ocho pétalos, a la que debió suceder un espacio de sintaxis metopada. Las características físicas de la pasta y el barniz, recuerdan muy de cerca las apuntadas en los $n .^{\circ 5} 1$ y 2.

\section{ESTUDIO}

El volumen global de los materiales de procedencia hispánica, presenta un amplio predominio numérico sobre el conjunto de la Terra Sigillata producida por el yacimiento. Así sobre las cifras totales barajadas hasta el presente (3.058 fragmentos), las piezas de fabricación hispánica representan un 61,16 por 100 (2.054 ejemplares). Con ocasión de este primer avance sobre la Terra Sigillata ofrecida por el asentamiento, hemos procedido a una muestra selectiva del nutrido conjunto integrado por los materiales desprovistos de contexto.

En espera de los resultados ofrecidos por los análisis físico-químicos actualmente en curso de realización, ha sido posible aislar por métodos más tradicionales, la presencia de dos focos principales de abastecimiento. El primero y más numeroso de ellos, documenta la existencia de importantes conexiones con el centro de producción de Andújar. El predominio cuantitativo arrojado por el material de esta procedencia, debe enmarcarse en un panorama más general, dado que los contactos entre nuestro yacimiento y el área bética vienen siendo habituales, tal y como parece avalar la nutrida presencia de materiales de otra índole, entre los que cabría destacar lucernas, cerámica de paredes finas o imitaciones de barniz rojo. 

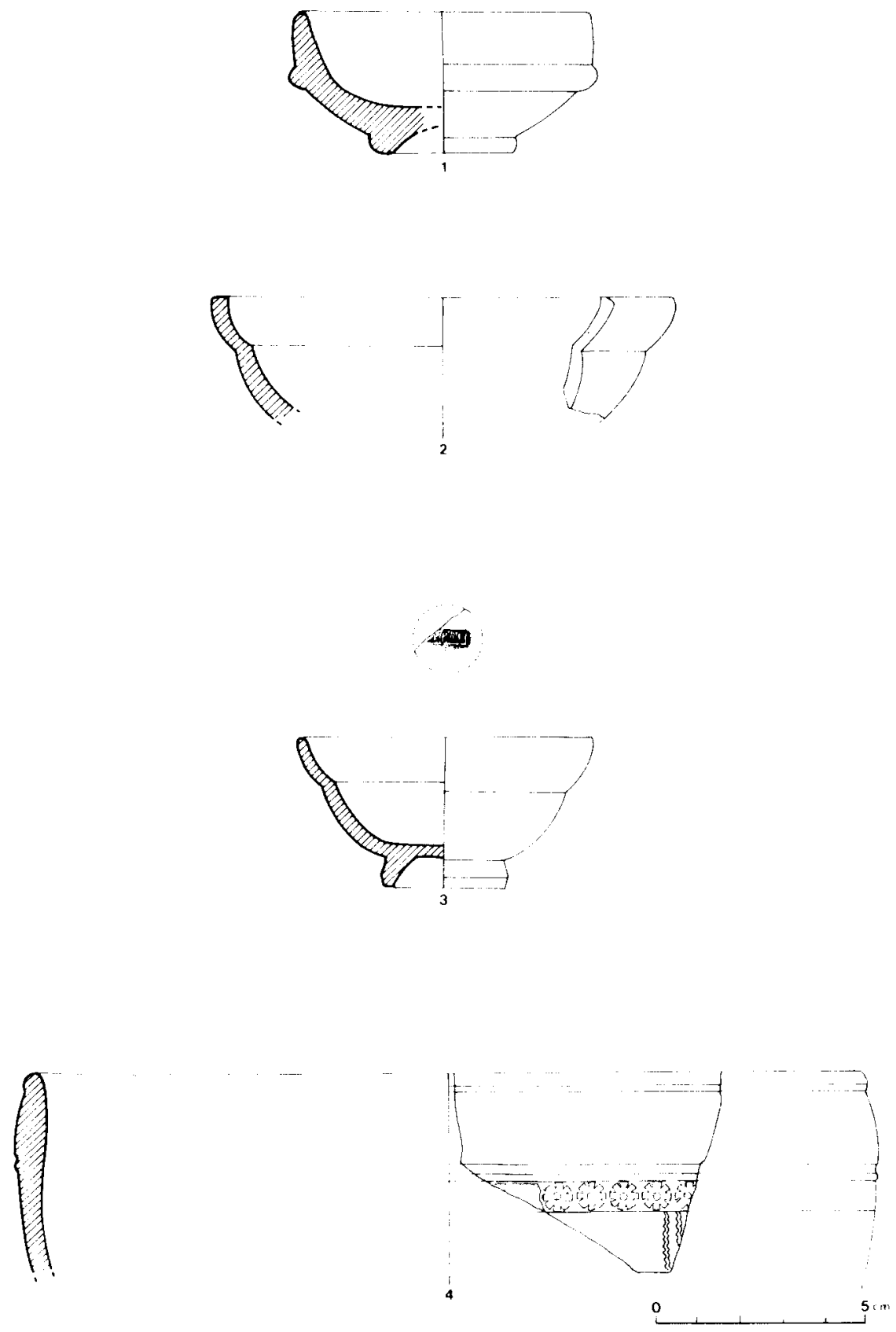

Fig. 22. 
Por otra parte, existe clara constancia de que el yacimiento sisaponense no fue ajeno al área de distribución de los potentes centros riojanos. Aunque en menor volumen, ha podido documentarse la presencia de un conjunto material nada desdenable, que contribuye a ampliar los datos conocidos sobre las relaciones comerciales existentes entre ambas zonas (GARABIto et alii 1988, 131-132).

En proporción casi insignificante, constatamos la existencia de algunos ejemplares, cuyas características externas impiden su atribución a cualquiera de los núcleos alfareros citados. Los análisis de composición permitirán en su momento ampliar más detalles, si bien tenemos noticia del funcionamiento de centros productores en la Meseta Sur, aún no demasiado bien conocidos (Sánchez-Lafuente 1985, 94).

\section{TSH PROCEDENTE DEL CENTRO DE PRODUCCIÓN DE ANDÚJAR}

El número total de piezas analizadas atribuibles a este núcleo alfarero se eleva a 52 ejemplares. Cabe anotar de entrada, el grado de superioridad numérica de las formas lisas sobre las decoradas, representadas por 43 y 9 fragmentos respectivamente. Entre las primeras, los tipos más abundantes corresponden a las formas Drag. 15/17 y Drag. 27.

Con el plato de forma Drag. $15 / 17$ hemos podido relacionar 19 ejemplares. El grado de conservación de sus perfiles ha permitido documentar la evolución formal constatada por $\mathrm{M}$. Roca en el yacimiento giennense. En este sentido, ha resultado posible identificar al menos en dos de nuestros ejemplares, la variante más temprana de esta forma en Andújar (fig. $6, n{ }^{\text {os }} 1$ y 2). Se trata de piezas cuyos rasgos morfológicos parecen reivindicar contactos con las producciones gálicas de época claudia y flavia (Roca 1976, 34). En ambos casos, parece destacable la molduración de la pared, asi como la presencia de pie anular elevado y fondo interno con abultamiento central.

Gran parte de las restantes piezas ofrecen caracteres análogos a los del segundo grupo establecido por Roca, equivalente el plato Drag. 15/ 17 típico de fabricación hispánica. En el conjunto inscrito en tal categoría pueden documentarse perfiles situables a comienzos del siglo $\| \mathrm{d} . \mathrm{C}$., como el del n. ${ }^{\circ} 9$ por citar el más completo, junto a otros más evolucionados (fig. 9, n. ${ }^{\circ} 1$ y 2). El ejemplar más tardio (fig. 9, núm. 3), presenta ya un pie prácticamente inexistente al exterior, pared muy exvasada de perfil acampanado y moldura casi imperceptible en el punto de articulación entre la pared y el fondo interno.

La constatación de este proceso evolutivo en Andújar, permite adelantar el momento inicial de la producción de esta forma, tradicionalmente 
situada a partir de mediados del siglo I d.C. (MezouiRIz 1961, I, 55). En efecto, una vez argumentada la relación formal existente entre el primer grupo y los prototipos gálicos de época claudia e incluso preclaudia, no parece inverosimil defender un breve margen temporal, entre las imitaciones y los productos inmitados (RocA 1976, 36). Estas apreciaciones cronológicas han sido corroboradas por posteriores investigación sobre los talleres riojanos (GARABito 1978, 57).

La forma mejor representada en el sector analizado es el bol Drag. 27, identificado en 17 ocasiones. Las características formales proporcionadas por este conjunto, se adaptan a las descritas como generales para la producción andujareña. Cabe destacar la presencia, en algunos de nuestros ejemplares (fig. 10, n. ${ }^{\circ} 5$; fig. $12, n .{ }^{\circ} 3$ y fig. 13, n. ${ }^{\circ}$ ) de una moldura poco marcada en el punto de unión entre el pie y el fondo externo. Este rasgo considerado habitualmente como impropio del centro giennense, ha podido ser documentado en el mismo yacimiento de Andújar sobre dos ejemplares (RocA 1976, 40, fig. 19, n. ${ }^{\circ} 43$ y 45).

El marco temporal de vigencia de esta forma en el centro bético, parece coincidir con la señalada para el plato Drag. $15 / 17$, si bien no ha sido posible aislar un grupo de rasgos tempranos, equivalente al de la última forma citada. El momento inicial de la producción puede situarse bien avanzado el siglo । d.C., manteniéndose durante el siglo II hasta el cese de actividad de estos alfares (Roca 1976, 40).

El bol de forma Drag. 24/25 ostenta una representación bastante reducida, limitada a 3 ejemplares. En conjunto se trata de un lote homogéneo, bastante adaptado a la descripción formal del tipo en Andújar (Roca 1976, 38). Únicamente uno de nuestros ejemplares (fig. 10, n. ${ }^{\circ}$ ), presenta rasgos morfológicos bastante cercanos a las produccions sudgálicas de época claudia, pudiendo corresponder por tal motivo, a los momentos iniciales de fabricación de la forma en el centro giennense (RocA 1976, 39). El fin de su producción podría situarse a comienzos del siglo II.

Menos representada se halla la forma Drag. 44, con tan sólo dos ejemplares (fig. 13, n. ${ }^{\circ} 5$ y 6). Este tipo poco frecuente en Andújar, presenta cronología avanzada tal y como documenta su presencia en las capas superficiales de los vertederos. Su producción inicial debe situarse en el siglo il d.C. y es probable que desapareciera en el curso de la misma centuria (RocA 1976, 43).

Finalmente cabe añadir la presencia de dos fragmentos asignables a las formas Hispánica 7 e Hispánica 14 (fig. 13, n. ${ }^{\circ} 7$ y fig. 14, n. ${ }^{\circ}$ 2). En la primera, escasamente documentada en Andújar, ha sido posible distinguir 
dos variantes de borde dotadas de cierto matiz cronológico. La ausencia de un borde levantado en nuestro caso, podría indicar que nos hallamos ante un ejemplar evolucionado. En cualquier caso, la forma carece de datación precisa, por lo que puede situarse grosso modo en el siglo I y quizá inicios del II d.C. (RocA 1976, 49). Por lo que respecta al segundo tipo, su presencia en Andújar ha sido reflejada muy recientemente en contextos datables en el siglo I d.C. (Mezquiriz 1985, 147, lám. XXIX, n. ${ }^{\circ}$ ).

Al margen de las atribuciones realizadas al centro de producción de Andújar mediante el sistema tradicional, tal presencia resulta ampliamente respaldada por la abundancia de marcas de oficina relacionadas con este focc bético. El conjunto de superficie ha proporcionado un total de 9 marcas, entre las que hemos podido identificar 7. El sello EX. OF. G.I.C. aparece documentado sobre dos fragmentos asignables a la forma Drag. $15 / 17$ (fig. $6, n{ }^{\circ} 3$ y fig. $8, n .^{\circ} 5$ ). La dispersión de los productos ligados a esta oficina, como consta en el estudio individual de las piezas, do cumenta su presencia en el Norte de África.

También en dos ocasiones ha podido registrarse la marca EX OF CA (fig. 13, n. ${ }^{\text {s }} 2$ y 3), de probada procedencia andujareña (RocA 1976, 16 17). En ambos casos aparece vinculada a vasos de forma Drag. 27 , tal y como suele ser habitual entre los hallazgos pertenecientes a este alfarero.

Existe constancia además, de la presencia de las marcas EX. OF. P.T., EX O TIF y EX OF C.L., representadas por un ejemplar en cada caso. Las dos primeras aparecen consignadas sobre sendos fragmentos de forma Drag. 27 (fig. 13, n. ${ }^{\text {os }} 1$ y 4 respectivamente). El seguimiento de su dispersión ha sido oportunamente incluido en los estudios correspondientes.

Dentro de las formas decoradas, resulta interesante anotar el absoluto predominio del cuenco hemiesférico Drag. 37. Con esta forma ha sido posible relacionar al menos 6 fragmentos. Por lo que respecta a los estilos decorativos documentados por estos ejemplares, destacamos la ausencia de composiciones adscritas en el marco de las imitaciones de T.S.G. El esquema más frecuente es el de series de círculos alternantes con motivos verticales de separación (fig. $14, n{ }^{\circ} 4$; fig. $15, n{ }^{\circ} 1$ y 2 ). Existe así mismo representación del estilo metopado (fig. $14, n .{ }^{\circ} 5$ ). No añadiremos más datos al respecto, puesto que el estudio de los punzones y su filiación ha sido suficientemente abordado en el catálogo. En cuanto a cronología, la procedencia superficial de gran número de los ejemplares estudiados impide el apunte de marcos temporales precisos. La forma Drag. $37 \mathrm{co}$ mienza a fabricarse en Andújar entre los años 65-70 d.C., permaneciendo vigente hasta poco antes de la fecha de extinción de estos talleres en un 
momento avanzado de la segunda mitad del siglo ॥ d.C. (RocA 1976, 66 y 69).

\section{TSH PROCEDENTE DE LOS ALFARES RIOJANOS}

Por el mismo sistema de observación externa aplicado a la serie anterior, ha sido posible aislar un conjunto material atribuible a los talleres riojanos integrado por un total de 38 fragmentos.

La relación ente formas lisas y decoradas resulta bastante más equilibrada en esta serie, con 22 y 16 piezas respectivamente. Entre las primeras, cabe anotar la presencia de dos fragmentos de forma Ritt. 8 (fig. 16, $n .^{\text {as }} 1$ y 2) adaptados en líneas generales, a los rasgos morfológicos que definen este cuenco de fabricación hispánica (MEZQuiriz 1961, I, 52-53). La presencia de borde incurvado hacia el interior (fig. 16, n. ${ }^{\circ} 1$ ) o de una ranura interna en la zona próxima a éste (fig. 16 , n. ${ }^{\circ}$ ), parece situar nuestros ejemplares, en un momento no demasiado avanzado de la producción de esta forma. El punto de partida ha sido establecido a mediados del siglo । d.C., con importante grado de perduración extensible hasta el siglo IV d.C. (MEzQuIRIz 1961, I, 53). Otros autores rechazan esta cronología final tan avanzada, emitida por Mezquiriz sobre la observación de los cuencos tardíos de Corella (MAYET 1984, I, 70).

La forma Drag. 27 podría estar representada por 5 ejemplares. Tal atribución se ha planteado en términos de probabilidad, puesto que no ha sido posible contar con perfiles completos o algo significativos. Sin duda es el ejemplar n. 3 (fig. $16, n .{ }^{\circ} 3$ ), el que aporta la base provista de rasgos más tempranos, con pie anular elevado y ligero engrosamiento central del fondo externo. La ausencia de bordes o de fragmentos de pared, impide la extracción de mayores precisiones evolutivas. El marco cronológico establecido para esta forma resulta muy amplio, con una datación de partida situable hacia mediados del siglo । d.C., tal y como confirma su presencia en los niveles claudios de la estratigrafía de Conímbriga (DELGADO et alii 1975, 184). En cualquier caso, las características externas de los fragmentos analizados por nosotros no parecen corresponder a momentos demasiado tardios de esta producción (siglos III o IV d.C.) (MEZQUIRIZ 1961, I, 60).

Mejor documentadas y algo más numerosas se hallan las formas Drag. 35 y 36 . Con el bol Drag. 35 se relacionan 5 ejemplares (fig. $17, n$. ${ }^{\text {s }}$ $1-5$ ), inscritos en las características formales que definen el tipo (MEZQUIRIZ 1961, I, 63). La serie proporcionada por el yacimiento sisaponense, documenta la presencia de los tipos de labio vuelto (fig. 17. n. ${ }^{\circ}$ ) o lige- 
ramente inclinado hacia abajo (fig. $17, n{ }^{\circ}{ }^{\text {s }} 3-5$ ). Junto a estas características, resulta destacable la presencia de ranura interna a la altura del borde en dos de nuestras piezas (fig. 1 , n. ${ }^{\circ} 1$ y 5 ). Este rasgo formal, relacionable con las producciones sudgálicas que integran el servicio $A$ (VERNHET 1976, 14, fig. 1), no resulta frecuente en los ambientes hispánicos. Por lo que respecta a las decoraciones de barbotina, su presencia se encuentra constatada en 4 ejemplares, sin que podamos añadir mucho más, dada la exigüedad de los fragmentos.

E plato Drag. 36 se encuentra representado por 7 piezas, igualmente de procedencia superficial (fig. 17, n. ${ }^{\circ} 6$; fig. 18, n. ${ }^{\circ}$ 1-6). Entre ellos se detecta cierto predominio de las variantes de labio inclinado (fig. 17, n. 6 ; fig. $17, \mathrm{n} .^{\circ 5} 1,3,4$ y 5) sobre aquellos ejemplares que lo presentan de trayectoria horizontal (fig. $18, n .{ }^{\circ} 2$ y 6 ). El primer tipo parece relacionarse con un momento temprano de la producción (ROMERo 1985, 200), si bien no constatamos la tendencia general que vincula los bordes descendentes con las decoraciones a barbotina. Tal tipo ornamental, se encuentra presente en uno de los ejemplares de borde horizontal (fig. 18, n. $\left.{ }^{\circ} 2\right)$.

El margen cronológico propuesto para ambas formas, coincide en su momento inicial, situable en torno al reinado de Vespasiano (MEzQUIRIz 1961, I, 63; MAYET 1984, I, 74). El cese de su fabricación debió producirse también de modo simultáneo en torno a fines del siglo ॥ (ROMERO 1985, 202; MAYET 1984, I, 74), de tal modo que no parece probable admitir una excesiva prolongación temporal para la forma Drag. 36, tal como propuso en su día M. A. Mezquiriz (MezquiRiz 1961, I, 64-65).

Remataremos esta síntesis sobre las formas lisas, subrayando la ausencia de marcas de oficina relacionables con los centros najerillenses, en el sector del yacimiento sometido a estudio.

Por lo que se refiere a los ejemplares decorados, ya se hizo constar con anterioridad, su posición numérica equilibrada respecto a los lisos. La forma mejor representada es la Drag. 29 con la que podrian relacionarse 9 ejemplares. Morfológicamente se detectan ciertas variantes de perfil, que afectan en su mayor parte, a la trayectoria más o menos exvasada del borde. Así junto a fragmentos de borde abierto, netamente destacado de la zona superior de la pared (fig. 19, n. ${ }^{\circ} 4,5$ y 7 ), aparecen otros ejemplares de borde apenas desplazado (fig. 19 , n. ${ }^{\circ}$; fig. 20, n. $^{\circ} 1$ y 2 ).

Al margen de aquellas piezas que han perdido toda evidencia de su decoración original, el esquema ornamental más frecuente es el metopado. En algunas de estas composiciones continúa advirtiéndose cierto influjo gálico, ya sea en la presencia de elementos aislados, como motivos 
cruciformes (fig. 20, n. ${ }^{\circ}$ ) o en la propia concepción de los paneles, mediante subdivisión de los mismos o de la repetición de un mismo motivo decorativo (fig. $20, n^{\circ} 2$ y 4 ). Estas reminiscencias reivindican una cronología no demasiado avanzada para las piezas de La Bienvenida. Por otra parte, la filiación de los punzones documentados, remite en gran parte de los casos, a paralelos con zonas de probado abastecimiento riojano - con los propios talleres del valle del Ebro.

A la forma Drag. 30 se han adscrito 2 fragmentos (fig. $20, n{ }^{\circ s} 6$ y 7 ). El más completo, correspondiente a la base (fig. $20, n .^{\circ} 7$ ), presenta las características formales propias de este vaso cilíndrico (MezQuiriz 1961, I, 95). La zona conservada en ambos, resulta demasiado exigua como para aludir a sus aspectos ornamentales. Únicamente puede afirmarse a este respecto, que ambas poseyeron esquemas metopados.

Más numerosa resulta la forma Drag. 37, constatada en 5 ocasiones. Las dos variantes que afectan al borde se encuentran representadas en la serie sometida a estudio, si bien el tipo de borde almendrado sólo ha sido documentado en una ocasión (fig. $21, n .{ }^{\circ}$ ).

En cuanto a estilos decorativos, predomina el de metopas (fig. $21, n{ }^{\text {os }}$ 1,2 y 4), aunque también está presente el de círculos alternantes con motivos verticales (fig. $21, n \cdot{ }^{\circ} 3$ ). Las piezas más tempranas son aquéllas que incluyen en su decoración elementos propios de los repertorios decorativos gálicos, tales como motivos cruciformes, punzones repetidos, etc. (fig. $21, n .{ }^{\circ}$ ). Un caso significativo del mantenimiento de elementos galos tamizados por la estética hispánica, es el representado por la pieza n. ${ }^{\circ} 36$ (fig. 21, n. ${ }^{\circ}$ ). Aparece en ella un gallón convertido en elemento vertical secundario, de tal modo que este motivo tan repetido por los alfares del Sur de Francia sobre la zona inferior de los vasos de forma Drag. 29, ha sido adoptado aisladamente, sobre una forma y en una composición que nada tiene que ver con el estilo original.

Por lo que respecta a la datación de esta forma, partiremos de la base, aceptada por todos cuantos se han ocupado del tema, de un inicio sincrónico para las variantes de labio almendrado y simple (MEZQuIRIz 1961, I, 106-107; Delgado et alii 1975, 159; Roca 1976, 69; Garabito 1978, 48; MAYET 1984, I, 84). Este momento inicial ha sido situado en torno al año 70 d.C. por los autores citados. Una fecha algo más moderna $-75-80$ d.C. - propugna Romero, de acuerdo con sus modificaciones en la cronología de la forma 29 (ROMERo 1985, 166).

La variante almendrada presenta con seguridad, una vigencia temporal más limitada, cuyo final puede situarse en la primera mitad del siglo I, según confirman los hallazgos portugueses y españoles (DELGADo et alii 1975, 159; ROCA 1976, 69). 


\section{CONSIDERACIONES FINALES EN TORNO A LA TERRA SIGILLATA SUPERFICIAL DE SISAPO}

La cronología genérica de los materiales sometidos a estudio, ha sido establecida a partir de criterios tipológicos y decorativos.

En efecto, una valoración global del conjunto, hace posible establecer tres etapas en la vertebración de las tendencias comerciales referidas específicamente a la Terra Sigillata. La primera de ellas ha de relacionarse sin duda, con el período augusteo y tiberiano. En este momento el grueso del material, corresponde a producciones de origen itálico y provincial. El horizonte más antiguo se halla representado por escasas evidencias pertenecientes a las formas precoces y especialmente, por los productos itálicos clásicos. Debe destacarse a este respecto, la total ausencia de elementos relacionables con los tipos arcaicos.

A partir de época de Tiberio y en convivencia con elementos itálicos de cronología más avanzada, comienza a detectarse una tímida presencia de productos de filiación gálica, que se tornará masiva en tiempos de Claudio. En este momento se registra un importante volumen de materiales que acreditan relaciones con el centro ruteno de La Graufesenque.

La presencia de productos gálicos comienza a experimentar un receso con posterioridad al reinado de Nerón, que se ha de convertir en fuerte caída desde el inicio de la época flavia.

Desde un momento situable en torno al último tercio del siglo I d.C., la práctica totalidad del material procede de los centros de fabricación hispánicos, que habían comenzado a entrar tímidamente en este mercado desde la fase anterior. De ellos el grupo más numeroso, es el procedente de Andújar, con interesante presencia de materiales vinculados al área de Tritium Magallum.

\section{BIBLIOGRAFIA}

Argente et alii (1980): Argente, J. L. El alli. Tiermes l, E.A.E., 111. Madrid

Beltran (1978): BeltRAN LloRis, M. Cerámina romana. Tipología y clasificación. Zaragoza.

Boube (1965): Boube, J., La terra sigillata hispanique en Mauretanie Tinqitane. Les marques de poitiers. Rabat-Maroc.

Borillo (1977): Burillo Mozota, F., “Hallazgos pertenecientes a época romana imperial en el "Campo Romano" (Zaragoza, Teruel)", Caesaraugusta, 41-42. Zaragoza.

DeCHELETTE (1904): Les vases céramiques ornés de la Gaule romaine. París

Delgado et alii (1975): Delgado, M.; Mayet, F.; Moutinho de Alarcao, A., Fouilles de Conimbriga IV. Les sigillées. Paris.

Domergue (1967): Domergue. C., "Marcas de alfarero en Terra Sigillata procedentes de Castulo y aportaciones al estudio de la "terra sigillata" hispánica de tipo B". Oretania, XXV-XXVII.

DRoumot (1966): Drouhot, J.. «Trouvailles antour de Chellah», BAM, VI. 1966. 
Fernandez Ochoa et alii (1990): Fernandez Ochoa et alii. Sis apo l. Excavaciones en el yacimiento iberorromano de La Bienvenida (Almodóvar del Campo, Ciudad Real). Memoria presentada a la Consejería de Cultura de la Junta de Comunidades de Castilla-La Mancha, para publicación.

Fernandez Martinez (1982): Fernandez Martinez, V., "El taller de Terra Sigillata de Tiermes", Homenaje a Almagro Basch. Madrid.

Garabito (1978): Garabito, T., "Los alfares romanos riojanos. Producción y comercialización", Bibliotheca Praehistórica Hispana, XVI. Madrid.

Garabito et alii (1988): Garabito, T; Solovera, E.; Pradales, D., "Los alfares riojanos y la comercialización de sus productos en la región de Castilla-La Mancha", I Congreso de Historia de Castilla-La Mancha, IV. Ciudad Real.

Garcia Guinea (1959): Garcia Guinea, C., "Prospecciones en la antigua Uxama (Osma)». AEsp.Arq., XXXII. Madrid

MANANes (1976): Mananes, T. "Materiales romanos de la villa romana de El Soldán, Santa Colomba de Somoza, León", Sautuola, II.

-1983: Mananes. T. Arqueología vallisoletana, II. Torozos, Pisuerga y Cerrato. Valladolid 1983

Martin-Serres (1970): Martin. G.; Serres, M. D., "La factoría pesquera de Punta de L'Arenal y otros restos romanos de Jávea (Alicante)". SIP, 38. Valencia.

MAYET (1970): MAYET, F., "A propos de deux potiers de Mérida: Valerius Paternus et Lapillius (Problèmes de méthode)", Mélanges Casa Velázquez, VI.

- (1984): Les céramiques sigillées hispaniques. Contribution à / histoire économique de la Péninsule lbérique sous l'Empire Romain. París.

Mezouiriz (1961): Mezquiriz, M. A., Terra Sigillata Hispánica. Valencia

- (1985): "Terra Sigillata Ispanica", Atlante delle Forme Ceramiche, Enciclopedia dell'Arte Antica Classica e Orientale. Roma.

Oswald-Pryce (1966): Oswald, F.; Pryce, D., An Introduction to the study of Terra Sigillata. $1 .^{\text {a }}$ ed. en 1920. London.

Pérez Almoguera et alii (1988): Pérez Almoguera, A.; Amare T.; Garces, I.; Marco, i. Els materials del jaciment romá de Raimat. Lleida.

Pérez Gonzalez (1989): Pérez Gonzalez, C., Cerámica romana de Herrera de Pisuerga (Palencia, España). La terra sigillata. Universidad Internacional SEK. Santiago de Chile

Roca (1976): Roca, M. Sigillata Hispánica producida en Andújar (Jaén). Jaén.

Romero (1985): Romero Carnicero, M. V., Numancia I. La terra sigillata. EAE, 146. Madrid.

Sanchez-Lafuente (1985): Sánchez-Lafuente Pérez, J., Comercio de ceramicas romanas en Valeria. Cuenca.

-- (1990): Terra sigillata de Segóbriga y ciudades del entorno: Valeria, Complutum y Ercávica. Madrid

Sotomayor (1972): Sotomayor, M., «Andújar (Jaén), centro de producción y exportación de sigillata a Mauritania". NAH, Arq., I. Madrid

-... (1977): Marcas y estilos en la sigillata decorada de Andújar. Jaén.

VERNHET (1976): "Création flavienne de six service de vaisselle à la Graufesenque", Figlina, 1, págs. 13-27. 